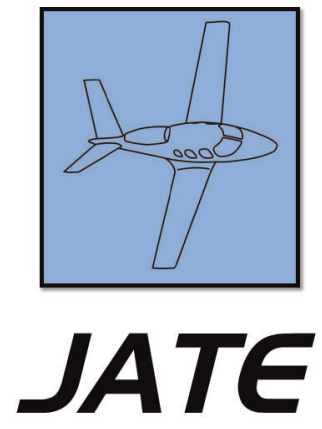

Journal of Aviation Technology and Engineering 7:1 (2017) 19-44

\title{
Design of DC-Link VSCF AC Electrical Power System for the Embraer 190/195 Aircraft
}

\author{
Eduardo Francis Carvalho Freitas \\ ETEP - Faculdade de Tecnologia de São José dos Campos, Brazil \\ Nihad E. Daidzic \\ AAR Aerospace Consulting, LLC
}

\begin{abstract}
A proposed novel DC-Link VSCF AC-DC-AC electrical power system converter for Embraer 190/195 transport category airplane is presented. The proposed converter could replace the existing conventional system based on the CSCF IDGs. Several contemporary production airplanes already have VSCF as a major or backup source of electrical power. Problems existed with the older VSCF systems in the past; however, the switched power electronics and digital controllers have matured and can be now, in our opinion, safely integrated and replace existing constant-speed hydraulic transmissions powering CSCF AC generators. IGBT power transistors for medium-level power conversion and relatively fast efficient switching are used. Electric power generation, conversion, distribution, protection, and load management utilizing VSCF offers flexibility, redundancy, and reliability not available with a conventional CSCF IDG systems. The proposed DC-Link VSCF system for E190/195 delivers several levels of 3- $\phi$ AC and DC power, namely 330/270/28 VDC and 200/ 115/26 VAC utilizing 12-pulse rectifiers, Buck converters, and 3- $\phi$ 12-step inverters with D-Y, Y-Y, and Y-D 3- $\phi$ transformers. Conventional bipolar double-edge carrier-based pulse-width-modulation using three reference AC phase signals and up to $100 \mathrm{kHz}$ triangular carriers are used in a manner to remove all even and many odd super-harmonics. Passive low-pass filters are used to remove higher harmonics. The RL AC loads are active in connection with the synchronous and induction AC motors and also include passive AC loads. The overall power factor exceeded 85\%. Total harmonic distortions for voltages and currents are below 5\%, thus satisfying the MIL-STD-704F and the IEEE Std. 519 power-quality standards, while avoiding the need for active filters. Several PI and PID controllers that regulate synchronous generator DC excitation and inverter banks were designed and tuned using the continuous-cycle tuning method to offer required performance and stability of the feedback loop. Mathworks's Simulink ${ }^{\mathrm{TM}}$ software was used for simulation of electrical components and circuits. Several critical scenarios of aircraft operations were simulated, such as go-around, to evaluate the transient behavior of the VSCF system.
\end{abstract}

Keywords: transport-category aircraft electrical power systems, electrical DC-link VSCF power systems, pulse-width-modulation, power inverters, power electronics, insulated gate bipolar transistors, tuning of PI controllers, total harmonic distortion, passive filters

All correspondence concerning this article should be directed to Nihad Daidzic at aaraerospace@cs.com. 


\section{Introduction}

The electrical system is one of the major non-propulsive power systems in transport category (T-category) FAR/CS 25 aircraft. The main purpose of the electrical system is to provide power for a plethora of electrically driven pumps (hydraulic fluid, fuel, lubricants, coolants, etc.), compressors (pneumatic air), fans (cooling, environmental cabin control, etc.), heating, and anti-icing equipment. Additionally, low-voltage power (28 VDC or $26 \mathrm{VAC}$ ) is provided for numerous redundant computer systems (flight and engine control, etc.) and various avionics (Aviation Electronics) systems (Moir, Seabridge, \& Jukes, 2013). This includes navigation and communication equipment. Last but not least, electric power is needed for lighting systems (14 CFR 25.1381 through 25.1387) and proper functioning of much of the miscellaneous equipment (14 CFR 25.1431 through 25.1461; electrical wiring interconnection systems are covered in 14 CFR 25.1701 through 25.1733). The other two major non-propulsive aircraft power systems are hydraulic and pneumatic (Moir \& Seabridge, 2008; Wild, 2008).

Design and certification of T-category electrical systems is governed by 14 CFR 25.1351 through 25.1365 (FAA, 2014). Similarly, EASA's CS 25 Subpart F (Equipment), 25.1351 through 25.1365 , regulations must be followed when designing and certifying electrical systems for T-category airplanes under its jurisdiction (EASA, 2007). The Air Transportation Association of America (ATA) specification 100 identifier 24 (electrical power) is used to classify aircraft electrical systems (Davies, 2003). Typically, IEEE 519 (IEEE,
1992) and MIL-STD-704F (US DOD, 2008) are utilized as guidance when designing aircraft electrical and electronic components.

Historically, direct current (DC) electrical systems were sufficient for small single- and twin-engine airplanes (FAR/ CS 23 certified), typically rated at 12 or 24 VDC battery (lead-acid or Ni-Cd) or equivalent 14/28 VDC alternators/generators. Considering that maximum sustained currents were limited to about 400 amperes for prime-mover starters, a 28 VDC system was able to deliver about $12 \mathrm{KW}$ (16 HP) per channel. With the growth of commercial civil aviation and the need for more electrical power, single- or multiphase, $115 \mathrm{VAC}$ (alternating current) systems operating at $400 \mathrm{~Hz}$ were developed. Several historical and tech 'nical reasons for the choice of that particular voltage and frequency are described in Moir and Seabridge (2008). The main reason is the reduction in required iron for windings, thus minimizing the weight of the electric machinery at higher frequencies. The growth of electrical power generation in civilian jet airplanes since the mid-1950s is illustrated in Figure 1. From about 1960 to 1990, the growth was practically stagnant. It is when the solid-state power electronics technology matured that an almost exponential growth in electrical power systems (EPS) capacity started.

Contemporary commercial transport-category airplanes certified under FAR/CS 25 (EASA, 2007; FAA 2014) traditionally use CSCF (constant speed and constant frequency) drives for the generation of $115 \pm 10$ VAC and $400 \pm 5 \mathrm{~Hz}$ three-phase (3- $\phi$ ), in mostly Y- (wye or star) configuration, currents with the $115 \mathrm{VAC}$ defining RMS phase voltage (line-to-neutral) and 200 VAC RMS line

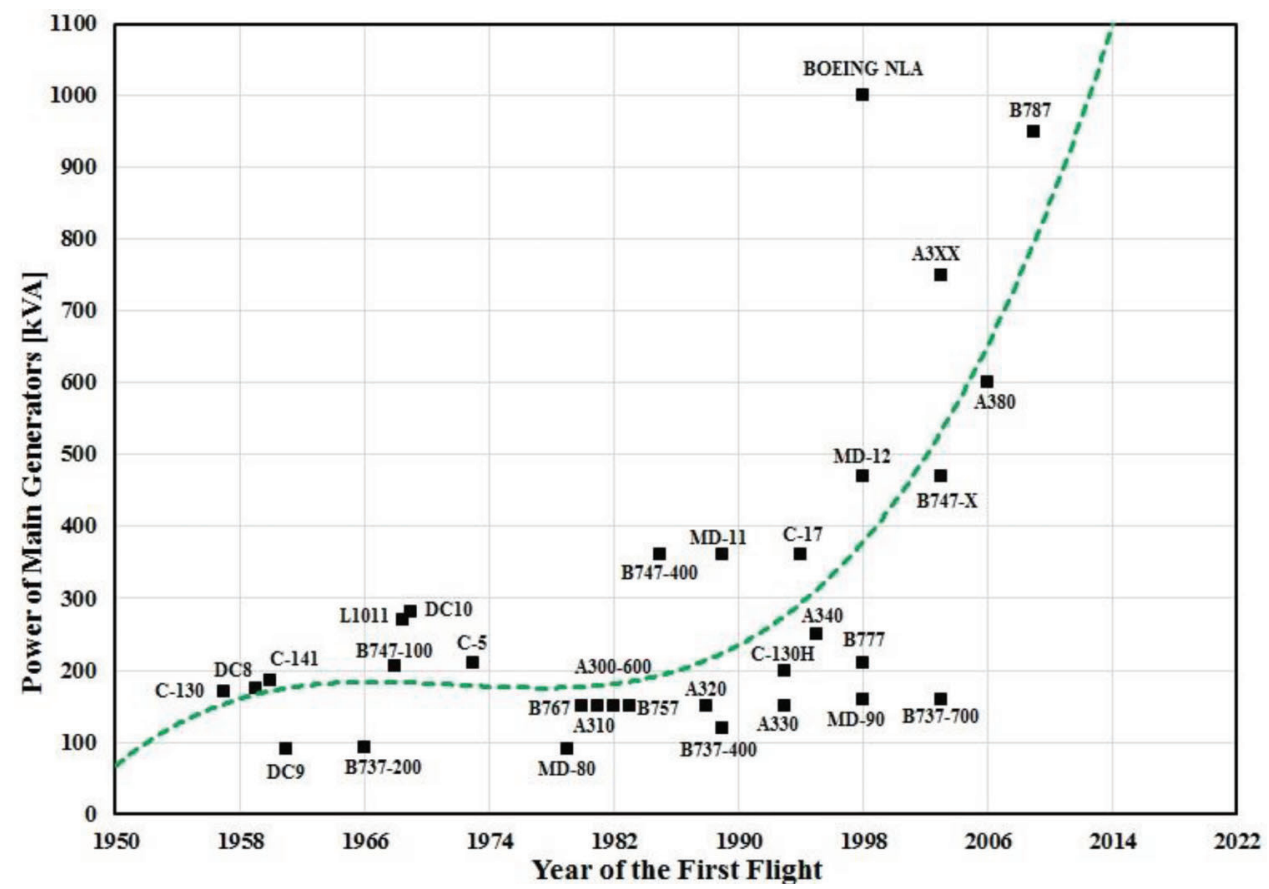

Figure 1. The growth of electrical power generation and consumption in commercial aviation for the past 65 years (source: Moir \& Seabridge, 2013). 
(line-to-line) voltages (Jeppesen, 2007). The current design implemented in many commercial transports is IDG (Integrated Drive Generator) containing hydraulic-transmission CSD (Constant Speed Drive) and AC generator all in one housing and mounted on the engine's external main gearboxes. The schematics of the IDG system is illustrated in Figure 2. However, CSDs are expensive to maintain and are not sufficiently reliable for modern airplanes. Many inflight IDG shutdowns due to CSD failures (e.g., lubrication problems) have occurred over the past several decades. Once shut down, the IDG AC generators cannot be restarted in flight, but only mechanically reconnected on the ground.

Generators used in most contemporary large transportcategory airplanes are compound-type brushless 3- $\phi$ AC generators-actually three machines in one (Jeppesen, 2007; Moir and Seabridge, 2008, 2013). They are synchronoustype generators (Appendix A) which use PMA/G (permanent magnet alternators/generators) in the first step to provide rectified DC for the field excitation and control of the final power-producing synchronous generator (SG). Turboprops (especially older ones) mostly use salient-pole frequency-wild brushed generators (Jeppesen, 2007). New switch-reluctance machines (SRM) are are gaining some prominence in aircraft electrical power generation (Moir \& Seabridge, 2008).

For the past 50 years there has been a trend to increase the percentage of electrical power generation with the primary goal to replace the pneumatic systems (other than perhaps for engine inlet anti-icing), which use bleed air from jet engine compressor stages. Studies have shown that it is more efficient to produce relatively more electrical power with more associated power offtakes in main engine gearboxes, than use bleed air for which already a significant amount of fuel was spent to accomplish the same system function. Using bleed air for air-conditioning and pressurization significantly reduces installed engine thrust. Hence, the new generation of aircraft such as the A380 and particularly the B787 can be termed MEA (More Electric Airplanes). The most modern MEA produce about one MVA $(1,000 \mathrm{kVA})$ in electric power. Even the hydraulic systems have been affected and scaled down due to new design philosophies. For example, A380 flight-control electro-hydrostatic actuators (EHA) use 3- $\phi$ AC power to feed power electronics and pumps (Moir \& Seabridge,

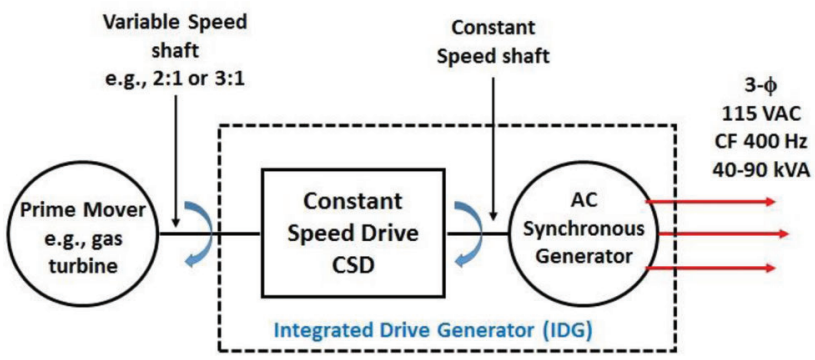

Figure 2. Schematics of IDG (CSCF) power generation and conversion.
2008). The primary flight control system becomes more distributive and works more efficiently with the flightby-wire systems, which could lead to elimination of one redundant hydraulic system. For various definitions of AC electrical terms and conversion efficiency, consult Appendix B.

For comparison, the very successful 1980s design B767 (-300 model) only produced $90 \mathrm{kVA}$ per channel plus the APU which also is rated at $90 \mathrm{kVA}$ (Moir \& Seabridge, 2008). About 30-years later, the B767's replacement, the B787 produces more than one MVA electrical power (Moir \& Seabridge, 2008), or $2 \times 250 \mathrm{kVA}$ starter/generators per engine at $230 \mathrm{VAC}$ phase voltage (400 VAC line voltage) and variable (or wild) frequency (VF/WF). Typically, VFs are in the range from 380 to $720 \mathrm{~Hz}$ (Moir \& Seabridge, 2008 ; 2013). Jet engine spools typically vary $2: 1$ in RPM ratios from ground idle to maximum thrust (TOGA). Additionally, the B787's APU powers 2 x $225 \mathrm{kVA}$ VF starter/generators at 230 VAC (Moir \& Seabridge, 2008).

Most APU turboshafts are speed governed. APUs are by their very nature constant-speed turbomachinery and do not require automatic hydraulic transmissions. They generate straight $400 \mathrm{~Hz}$ AC power. Such is the case for the A380 which has speed-governed APU powering 2 x $120 \mathrm{kVA}$ CSCF $400 \mathrm{~Hz} 115$ VAC SGs. A380 also has 4 x 150 kVA VF 115 VAC generators. Transformer rectifier units (TRU) are used to convert some of $230 \mathrm{VAC}$ power into $28 \mathrm{VDC}$ power for instruments and electrical equipment. Also B787 converts a lot of $230 \mathrm{VAC}$ into $115 \mathrm{VAC}$ to power legacy equipment. Such conversion is done efficiently using 3- $\phi$ step-down transformers (Fitzgerald et al., 2003). Interestingly, unlike A380 and B777, the B787 EPS design avoided the use of the emergency power RAT (Ram Air Turbine) as in-flight backup power. For example, the A380 uses $70 \mathrm{kVA}$ RAT for emergency power, while the B777 uses 2 x 20 kVA DC-Link VSCF backup power system. The B777 also uses about 13 different PMGs for emergency power supply. For more details on specific aircraft EPS design, consult Moir and Seabridge (2008) and Wild (2008).

Variable frequency AC can be used directly in all pure resistive loads (such as for electrical wing anti-icing, windshield heat, incandescent lighting, etc.), but the inductivecapacitive loads, such as motors, will need their own controllers for frequency/speed/torque control (Gottlieb, 1994). Additionally, VF currents can be rectified into 28 VDC with little regard to the original "wild" AC frequency. For example, this is also done in engine-mounted PMGs/PMAs, which supply rectified 28 VDC for FADEC emergency power supplies (Daidzic, 2012).

A method to reliably and efficiently generate VF AC at 115 or $230 \mathrm{VAC}$ and then use power electronics to convert that electrical power into $\mathrm{CF}(400 \mathrm{~Hz})$ has been entertained in several airplane types (civilian and military). Variable speed constant frequency (VSCF) EPS has been used in several previous airplane models, such as the B737-500, Bombardier's Global Express, and MD-90 (2 x 75 kVA). 
A backup 2 x $20 \mathrm{kVA}$ VSCF power converter also exists in the B777. Military aircraft more commonly use Cycloconverters for $\mathrm{AC} / \mathrm{DC} / \mathrm{AC}$ conversion. On the other hand, DC-Link VSCF AC/DC/AC conversion designs are more common in civilian aircraft applications (Moir \& Seabridge, 2008; 2013). The focus of this article is on the DC-Link VSCF systems.

A DC-Link VSCF AC-DC-AC system is illustrated in Figure 3. Conceptually the $\mathrm{VF} \mathrm{AC}$ is rectified into controlled DC (DC-Link) and then inverted back into desired AC with controlled CF. Voltages, currents, and power are controlled to meet load demands. While practical designs may vary, the most important issue is in obtaining efficient power conversion and transmission. Total Harmonic Distortion (THD) and low power factors (PF) cause increased copper loss and torque ripples and could also damage equipment. Each generating and converting device needs to be actively controlled (frequently with the proportional-integral or PI controllers), and many filters (such as low-pass) are required.

The main goal of this study is the conceptual design of a relatively inexpensive and reliable DC-Link VSCF AC-DC-AC power generation, conversion, and distribution system for an existing Embraer E190/195 regional-jet airplane. Although this is a work in progress, it is hoped that the final design solution will result in weight reduction combined with increased system reliability, redundancy, and operational flexibility, all while decreasing maintenance costs. As the power electronic switches and associated computer-controls become cheaper and more reliable, so will the proposed VSCF aircraft EPSs.

\section{Literature Review}

For the general layout and design of aircraft EPS, we used references by Davies (2003), Jeppesen (2007), Moir and Seabridge (2008; 2013), and Wild (2008). The basic theory of DC and AC electrical circuits, signal processing, solid-state pulsed circuits, and electrical machinery (motors and generators) was mostly used from Bell (1981); Fitzgerald, Kingsley, and Umans (2003); Fink and Christiansen (1989); Gottlieb (1994); Nahvi and Edminister (2003); and Phillips and Parr (1999). The references on power electronics theory and design were used from Bose (2002); Grigsby (2007); Hart (2011); Luo and Ye (2010); Mohan, Undeland, and Robbins (2003); and Mohan (2012). A good introduction into the theory and design of analog and digital filters is given in Hamming (1998) and Phillips and Parr (1999). The references used for the theory of automatic control, control systems engineering, adaptive and optimal control, and system dynamics were Aström and Wittenmark (2008; 2011), Kilian (2006), Kirk (2004), Nise (2011), Netushil (1987), Ogata (2004), and Tewari (2005). The theory of Pulse Width Modulation (PWM) was mostly consulted from Bose (2002), Holtz (1994), Mohan et al. (2003), and Sun (2012). Essentials of signals and frequency analysis were consulted from Phillips and Parr (1999). Mathematical theory of Fourier series and related topics were checked from Abramowitz and Stegun (1984) and Tolstov (1976). Technical details on E190/195 and its EPS design and operations were extracted from Embraer's original AOM (Airplane Operations Manual) and aircraft maintenance manual (Embraer, 2010, 2015). Review articles describing the state-of-the-art and future trends on aircraft electrical power systems and associated technologies are given in Abdel-Fadil, Eid, and AbdelSalam (2013); Abdel-Hafez and Forsyth (2009); and Abdel-Hafez (2012).

One of the earliest contributions to mathematical modeling and simulation of VSCF aircraft's electrical power generating systems was given by Vadher, Smith, and Williams (1986). DC-Link converters were analyzed as a substitute to then existing $\mathrm{CS} / \mathrm{CF}$ drives. A six powertransistor inverter with parallel-connected commutating diodes was operated in PWM mode to reduce the harmonic content of the output voltage. Additionally, input and output filters were used with the inverter to further reduce undesired harmonics. Another early contribution in designing solid-state VSCF power converters for airplanes was given in a thesis by Rahal (1991). The author provided many technical details and conducted test-rig experiments with a three-phase PWM MOSFET-inverter. To protect MOSFETs, snubber circuits were designed. To eliminate the problem of slow recovery of MOSFET switches, Schottky diodes and the fast-recovery diodes have been used. Blanking circuits were designed as well. Andrade and

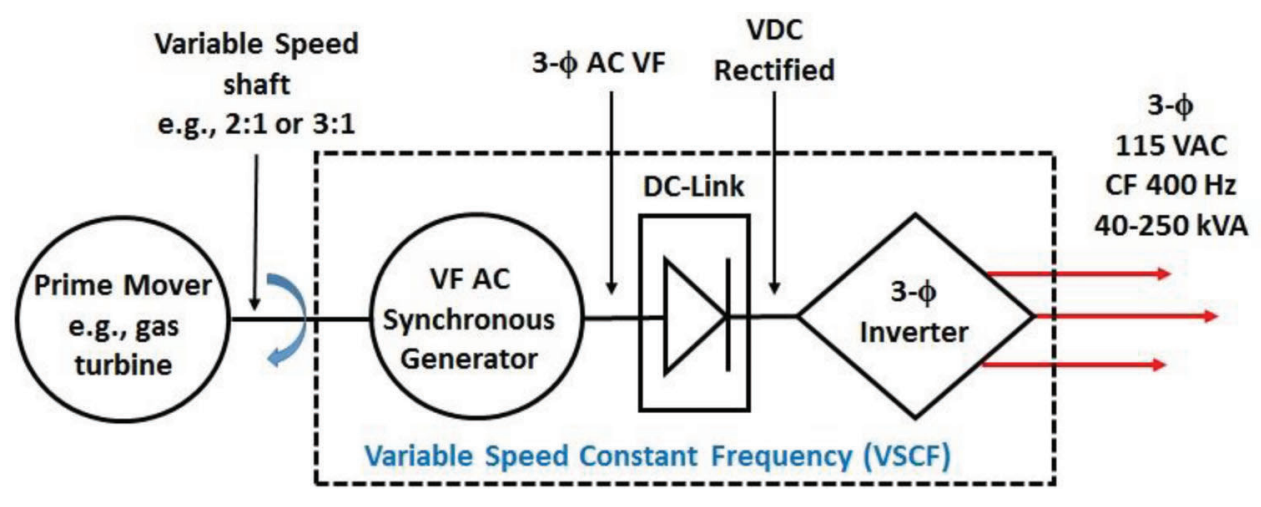

Figure 3. Schematics of DC-Link VSCF power generation and conversion. 
Tenning (1992) reported on early designs of B777 EPS, which also included VSCF DC-Link EPS backup of $20 \mathrm{kVA}$. Also a new redundant two-way communication bus ARINC 629 was developed specifically for use in B777 to communicate between various control units, monitor, and provide built-in-test information (Andrade \& Tenning, 1992; Moir, Seabridge, \& Jukes, 2013). Shiao and Lin (1995) proposed a compact induction-type generator for VSCF aircraft electrical system IGVSCF). The authors used the familiar $d q 0$-axes generator model, RL loads model, and (5 kVA three-phase $110 \mathrm{~V}$ ) PWM inverter model. The authors claimed that the compact induction generator VSCF (IGVSCF) system presented could increase efficiency and reliability and further reduce the required maintenance manpower per flight hour. The performance of the IGVSCF system was simulated by the computer program and the experimental operation performed on a prototype IGVSCF system. The simulated results and experimental tests demonstrated higher efficiency of IGVSCF compared to more conventional designs. The thesis by Jadric (1998) is interesting as the VSCF system was designed utilizing the ground-based variablespeed gas-turbine for electrical power generation. A system analyzed consisted of a variable-speed SG that supplies an active DC load to inverter through a 3- $\phi$ diode rectifier required adequate modeling in both time and frequency domain. The average model developed accounts for dynamics of generator and load, and for effects of the non-ideal operation of diode rectifier. The model is nonlinear, but time continuous, and can be used for large- and small-signal analysis.

Gong and colleagues (2005) performed comparative evaluation of 3- $\phi$ high power-factor AC-DC converter for future MEA applications. The authors used passive 12-pulse rectifier, two- and three-level active PWM rectifiers to analyze DC-Link used to supply $5 \mathrm{~kW}$ power to a variablespeed hydraulic pump. Eid and colleagues (2010a, 2010b) conducted an investigation of power quality of a VSCF DC-Link system for aircraft EPS. The authors demonstrated the application of VSCF by 12-pulse converters and power passive filters in the power generation in the aircraft electrical system. The output power for the simulation and design was similar to a Boeing 767 with two channels of $90 \mathrm{kVA}$. To obtain results, several load combinations were used. Passive and dynamic AC loads and DC loads were applied to simulate the design. An EPS was designed with a SG that has an output of 360 to $800 \mathrm{~Hz}$ frequency range. A 12-pulse TRU was used in the output of the generator in order to obtain DC voltage. The 12-pulse converter was chosen because it has inherent high PF and low THD. The regulation of TRU was conducted utilizing PI control to power a 270 VDC DC-bus. Three different DC loads were connected to the DC bus by DC/DC converters. A 12-pulse inverter was used to provide $200 \mathrm{VAC}$ at $400 \mathrm{~Hz}$ and a PI controller to regulate the right parameter in the AC bus. AC loads composed of three passive loads with 18, 2.6, and $15.5 \mathrm{kVA}$ of electrical power and three dynamic loads composed by motors of different electrical power (11.2, 7.5, and $5.0 \mathrm{~kW}$ ) were also connected to the $\mathrm{AC}$ bus.

El-Kishky, Ibrahimi, Abu Dakka, Eid, and Abdel-Akher (2011) present a comprehensive model of a VSCF aircraft electric power system with a large share of nonlinear loads. The model was used to study the performance of the system under different nonlinear loading conditions. Both transient and steady-state performance characteristics of the system were investigated and compared to applicable aircraft EPS standards (IEEE and military standards). Nya, Brombach, and Schulz (2012) discussed continuously increasing aircraft electrical power demands. New electric voltage levels are actually alluded to in order to respond to demand challenges. Many advantages of high voltage alternating current (HVAC) and high voltage direct current (HVDC) in an aircraft EPS (namely $230 \mathrm{VAC} \mathrm{CF/VF} \mathrm{and} \mathrm{+/-270} \mathrm{VDC,}$ or $540 \mathrm{~V} \mathrm{DC}$, between the positive and the negative potentials) are presented and compared with the conventional $115 \mathrm{VAC} \mathrm{CF} / \mathrm{VF}$ and $28 \mathrm{VDC}$ systems. Power quality, weight comparison, and applicability were exhibited at power generation, distribution, and load level. Issues regarding the simultaneous supply with HVAC/HVDC and associated current technology research were discussed.

Khaburi and Nazempour (2012) used the $d q 0$ model of a 2-pole, $30 \mathrm{~kW}$, line-to-line voltage $480 \mathrm{~V}, 96,000 \mathrm{RPM}$, PMSM (permanent magnet synchronous machine/generator) powered by a microturbine and the PWM rectifier to convert variable- and high-frequency AC generated by a variable-speed (VS) microturbine. Using a $2 \mathrm{kHz}$ carrier based PWM voltage source inverter (VSI) with six insulated gate bipolar transistors (IGBTs) and six anti-parallel diodes, DC was converted to high-quality AC with low THD. Harmonics in inverter output, centered on multiples of $2 \mathrm{kHz}$, were cleaned using an LC filter. The authors reported excellent dynamic response and decoupled control of active and reactive powers with the step change transient using virtual flux based direct power control (VF-DPC). Trentin, Zanchetta, Wheeler, and Clare (2013) proposed AC-DC power conversion for a new generation of aircraft which distributes only DC power over 28 and 270 VDC (HVAC/HVDC). The source of electrical power is 360$900 \mathrm{~Hz}$ VF 230 VAC alternator and DC power at two different voltages acquired using the Buck rectifier/converter. Modeling and simulation of a three-phase voltage source inverter (VSI) using a model predictive current control was reported by Almaktoof, Raji, and Kahn (2014). Among other results, the dynamic response of the system with the step change was investigated using MATLAB/Simulink. Problems in electrical energy conversion from wind turbines are in many ways similar to the problems in electrical power generation in turbine-powered airplanes. The wind turbine generates AC power at changing frequencies (VF), which then must be converted into $\mathrm{CF}$ AC voltage for distribution and integration 
into the public electrical network. In that respect, the work by Malinowski, Milczarek, Kot, Goryca, and Szuster (2015) was very useful in choosing proper technologies and power electronics systems theory and practice.

\section{Methods and Materials}

We used Simulink ${ }^{\circledR}$, which is a powerful (pre-processor) graphical user-interface (GUI) to the MATLAB ${ }^{\circledR}$ (Mathworks, Natick, MA) software platform in our conceptual and preliminary designs and simulation of the DC-Link VSCF EPS for E190/195. Simulink ${ }^{\circledR}$ enables block-diagram representation of dynamic systems. More details on Simulink ${ }^{\circledR}$ and application examples in various engineering systems can be found in Karris (2008) and Tewari (2005). Other well-known simulation programs/software for electrical circuit analysis and design are SPICE, PSPICE, SABER, and EMTP (Nahvi \& Edminister, 2003; Mohan et al., 2003). However, many high-level programming languages, such as Fortran, $\mathrm{C}++$, Basic, Pascal, and the MATLAB platform can be used to solve the resulting system of differential and algebraic equations in time- and frequency-domains. Mohan et al. (2003) give a review of different modeling and simulation strategies when designing and solving circuit problems.

\section{Power Electronics Switches}

Solid-state power electronics has brought a small revolution in control of many medium- to high-power devices and electrical machines (e.g., speed control of induction or asynchronous motors). Many different solid-state switches, such as uncontrolled power diodes, thyristors (SCR, GTO, Triacs), and power transistors (BJT, MOSFET, IGBT, etc.) exist today (Bose, 2012; Hart, 2011; Luo \& Ye, 2010; Mohan et al., 2003). In our simulation of a new E190/195 EPS design, we utilized inverter banks employing IGBTs. Insulated gate bipolar transistors, which are hybrids of BJTs and MOSFETs, are today able to handle up to $4,500 \mathrm{~V}$ reverse-bias voltages and push through currents of almost 4,000 amperes. Effective power transferred in converters using IGBTs is nearing 6-10 MVA. IGBTs provide for rapid switching frequency (not as fast as MOSFETs, but faster than BJTs) with minimal loss of energy and are thus optimal for many switching applications. IGBTs have become an industrial standard in medium-to-high power converters, ousting BJTs in medium-power switching and currently ousting gate turn-off thyristors (GTOs) in high-power range (1-10 MW). IGBT converters are mostly snubberless, providing hard switching. Early IGBTs had latchup (turn-off) problems, but that is almost a non-issue today. Non-Punch Through (NPT) IGBTs are robust, offer better protection in the short-circuit protection, and can be realized for higher voltages than the punch through (PT) IGBTs. However, NPT IGBTs have a higher forward voltage drop compared to PT
IGBTs (Grigsby, 2007). All power semiconductor devices, including IGBTs, are commonly protected against latching (IGBT), voltage spikes and gate over-voltage, over-current, excessive $d i / d t$, excessive $d v / d t$, electrostatic discharge, and high-temperatures (overheating).

In order to have a practical inverter design, power, and control circuits are required. The power circuit consists of IGBTs (e.g., insulated type HVIGBT Mitsubishi Electric Corporation CM1200HC-90R with collector current of 1,200 A, collector-emitter voltage of 4,500 V, and LPTIGBT with soft recovery diode), snubber circuits, gate drive, isolated power supplies, and isolation and blanking circuits (Rahal, 1991). The control circuits consist of filter circuits, three-phase sinusoidal wave generation circuits, triangular carrier wave circuits, and comparator circuits for PWM. Snubber circuits are often implemented to prevent too high electrical stresses, smooth out transients, limit voltages and currents during transient operation, and protect the switch from short-circuit conditions (Mohan et al., 2003). Of particular concern is the high rise of $(d i / d t)$ at device turn-on and high $(d v / d t)$ rise during device turn-off. Heat sinks and passive/active cooling have to often be added to power transistors to maintain acceptable operating temperatures.

In order to reduce voltage and/or current THDs, firstorder (one-pole) passive filters (RLC-type) are placed in series and parallel to remove higher (low-pass) and/or lower (high-pass) waveform harmonics. Also band-pass (BP) filters were used. Not only do the sub- and superharmonics reduce power of the power-carrying fundamental harmonic, but they also cause vibrations, noise, heating, and could damage electric equipment over time. Occasionally, active filters are necessary to keep THD down. A good discussion on active filters for power conditioning is given in Grigsby (2007).

\section{Current EPS on E190/195}

The Embraer E190/195 is the newest addition to the regional E-Jet family (which includes previous models 135/ 145 and 170/175). It is an FAA/EASA FAR/CS Part 25 certified narrow-body, medium-range, twin-engine jet airplane produced by the Brazilian aerospace conglomerate Embraer. The entire series was launched in 1999 and entered production in 2002. The aircraft is used mostly by regional air carriers. Over 1,000 units were ordered by the end of 2014. The Embraer 195 or ERJ 190-200 comes in standard and long range (LR) versions. The MTOW of the standard version is 48,790 $\mathrm{kg}(107,560 \mathrm{lb})$. Embraer 195 uses two 3,700 lbf heavy, twin-spool GE CF34-10E7 (GE EM-2005T12-01 type certificate sheet) medium-bypass turbofans certified in 2006. The maximum speed of the HP-spool $\left(\mathrm{N}_{2}\right)$ is 18,018 RPM. The bypass ratio is 5.4:1 and the engine delivers maximum of $20,360 \mathrm{lbf}(90.6 \mathrm{kN}$ or $9,060 \mathrm{daN}$ ) thrust during takeoffs. The specific fuel consumption (SFC) at cruise of Mach 0.8 and 35,000 ft pressure altitude is $0.64 \mathrm{lbm} / \mathrm{lbf} / \mathrm{hr}$ or $18 \mathrm{~g} / \mathrm{kN} / \mathrm{s}$. 
The E190 series EPS, illustrated schematically in Figure 4, is rather conventional using two $3-\phi 40 \mathrm{kVA} 115 / 200 \mathrm{VAC}$ (phase/line) IDGs powered by respective jet engines each and a third CF $40 \mathrm{kVA}$ 115/200 VAC generator powered by the APU. The AC electrical system is thus $\mathrm{CF}$ at $400 \mathrm{~Hz}$ at 115/200 VAC with three TRUs (rated at 300 Ampere each) delivering 28 VDC. There are two 22.8 VDC Ni-Cd batteries, each rated at $27 \mathrm{Ah}(616 \mathrm{Wh})$, powering respective hot battery buses. Embraer 190 uses 15 kVA 3- $\phi$ 115/ $200 \mathrm{VAC} 400 \mathrm{~Hz}$ RAT installed in a nose as an emergency in-flight power source. RAT can be deployed manually or automatically and restowed only on the ground. Abbreviations used in Figure 4 are described in Table 1.

A solid-state static inverter converts $28 \mathrm{VDC}$ into 115 VAC using the DC Essential-bus \#1 as a source and delivering conditioned power to the AC Essential-bus or AC Standby-bus. The E-Jet's EPS provides no-break power transfer (NBPT) by allowing momentary paralleling (for several milliseconds) between two power sources (IDGs,

Table 1

E190/195 electrical system abbreviations (source: Embraer).

\begin{tabular}{ll}
\hline Abbreviation & \multicolumn{1}{c}{ Description } \\
\hline ICC & Integrated Control-Center \\
RICC & Right Integrated Control-Center \\
LICC & Left Integrated Control-Center \\
EICC* & Emergency Integrated Control-Center \\
APU & Auxiliary Power Unit \\
DC/DC & DC-DC Buck Converter \\
VSCF & Variable Speed Constant Frequency \\
BTC & Bus Tie Contactor \\
DCTC & DC Tie Contactor \\
TRU & Transformer Rectifier Unit \\
BATT & Battery \\
\hline
\end{tabular}

Note: *EICC is normally integrated with LICC.

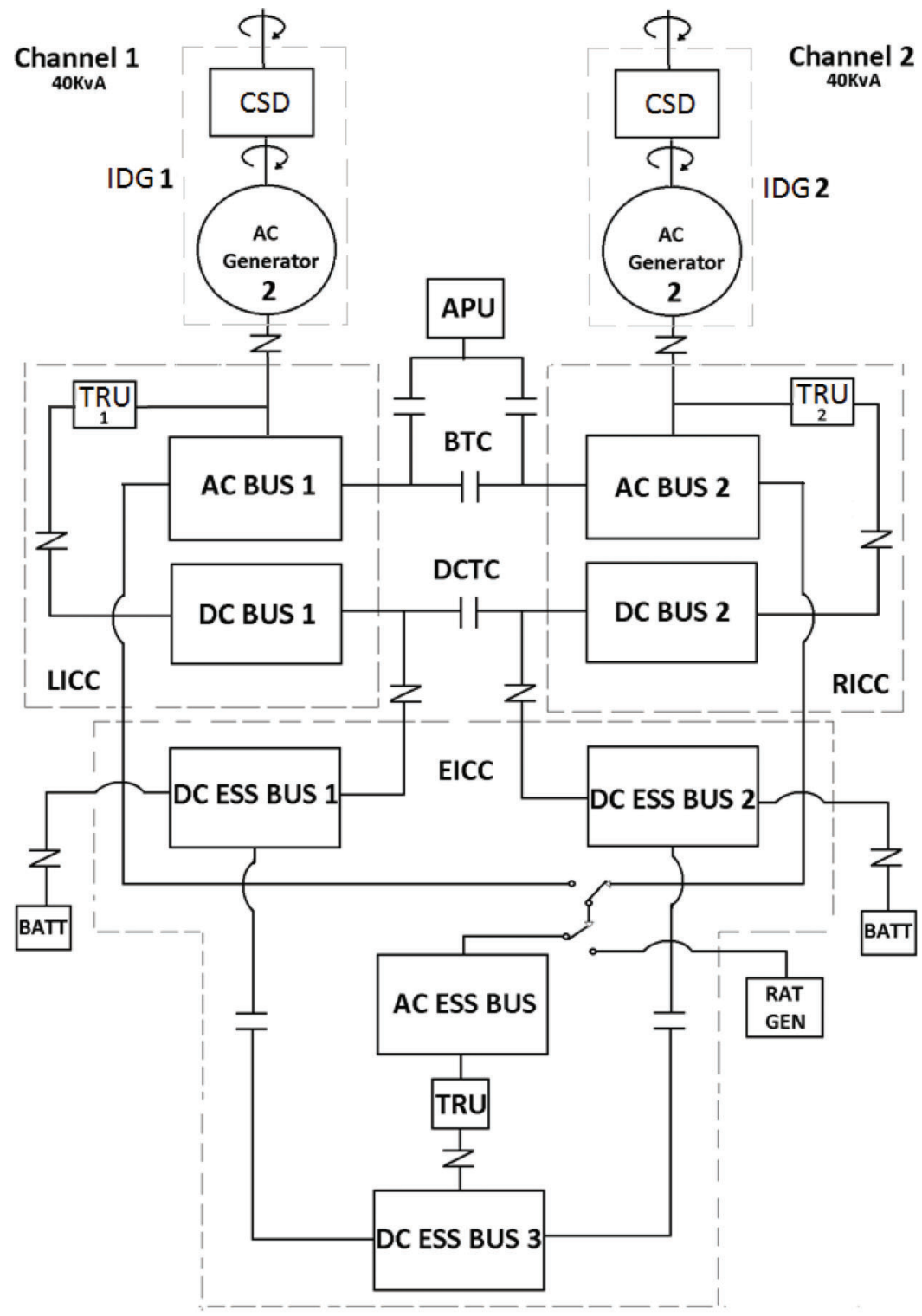

Figure 4. Embraer 190/195 current production EPS schematics during normal operation. 
GPU, APU) at any possible combination. E-190 also provides connectors for external 115 VAC GPU power source. An external DC GPU rated at 24 to $29 \mathrm{VDC}$ is also available for APU starting. More details and description of the entire E-190/195 can be found in AOM (Embraer, 2014), E-190/195 maintenance manual (Embraer, 2015), and other manufacturer's information.

\section{Proposed Embraer E190/195 VSCF DC-Link EPS Design}

A schematic layout of a new proposed E190/195 EPS utilizing DC-Link VSCF is illustrated in Figure 5. SGs rated at $40 \mathrm{kVA}$ and 115/200 VAC were chosen as the primary electrical power generators. The variable generator frequency (VF) is due to the ever-changing angular speed (RPM), which is connected to the engine's $\mathrm{N}_{2}$-spool (HP spool) shaft via reduction gears (main accessory gearbox). Synchronous generator $d q 0$ mathematical model is described in Appendix A. The output frequency $(\mathrm{Hz})$ of a 3- $\phi$ SG (Fitzgerald et al., 2003) links the driver's RPM (N) and the fixed number of poles-per-phase $(p)$ :

$$
f=\left(\frac{p}{2}\right) \times \frac{N}{60}
$$

Note that $p / 2$ stands for the number of pole-pairs per phase, while $N / 60$ is the number of revolutions per second (RPS $=$ RPM / 60). Desired output voltage is controlled by the generator field winding excitation governed by a dedicated PI controller (see Appendix C for controller tuning method). The desired frequency was supplied by a frequency generator using sinusoidal PWM and is part of inverter design. The generator output voltage is negativefeedback controlled in order to maintain constant voltage for DC-Link.

Two transformer rectifier units (TRU) are used to convert variable-frequency (VF) $115 \mathrm{VAC}$ at generator output into rectified and filtered 330 VDC. A 12-pulse diode rectifier was utilized because of its advantageous harmonic reduction property over simpler 6-pulse configuration. The harmonic order can be estimated from, $h=n p \pm 1$ where $p$ is now the number of pulses-per-cycle and $n$ is an arbitrary integer (Bose, 2002). Similar strategy was used by Eid et al. (2010a, 2010b). For a 12-pulse configuration, the $3^{\text {rd }}$ and $5^{\text {th }}$ harmonic orders are not present, just $11^{\text {th }}$ and $13^{\text {th }}, 23^{\text {rd }}$ and $25^{\text {th }}$, and so on. In order to obtain a real 12-pulse rectifier, a phase shift of $30^{\circ}$ is required. This can be easily accomplished using a D/Y/D transformer. The D/Y/D was chosen because it has a useful property of removing triple-order (third, ninth, fifteenth, twenty-first, etc.) odd harmonics (1, 3, 5, 7, etc.).

A 12-pulse forced-commutation controlled-IGBT inverter consists of two 6-pulse inverter bridges and was designed to transform $330 \mathrm{VDC}$ into a constant $115 \mathrm{VAC}$ at $400 \mathrm{~Hz}$, which is the standard AC electrical supply for E190/195 devices and equipment. In order to obtain 115 VAC, a particular minimum input VDC in the inverter is necessary (Equation 2). Considering the RMS output phase voltage to be $115 \mathrm{VAC}$ (200 VAC line) and the modulation index of sinusoidal PWM $m_{a}$ is unity (Bose, 2002; Mohan et al, 2003) results in a minimum of 325 VDC input voltage on DC-Link (Bose, 2002; Eid et al., 2010a, 2010b; Mohan et al, 2003):

$$
V_{R M S}=0.5 \times m_{a} \times \frac{V_{D C}}{\sqrt{2}} \quad m_{a}=\frac{V_{r}}{V_{c}}
$$

See Appendix D for basic definitions and technical details on PWM. The carrier wave consists of an isosceles triangular wave (Bose, 2002; Sun, 2012) with voltage $V_{c}$ and high frequency $f_{c}$, while the modulating/reference wave at the fundamental frequency $f_{1}(400 \mathrm{~Hz}$ here) has the peak value of $V_{r}$ (Bose, 2002). The PWM of the inverter was controlled by a conventional PI controller. This design was implemented in our Simulink ${ }^{\circledR}$ model.

PI and PID (proportional-integral-derivative) controllers were used to achieve the desired output signals in the inverter, DC-DC Buck converter, and in the field excitation control of SG. In order to obtain constant $330 \mathrm{VDC}$ in a DC-Link channel a dedicated PI controller was implemented. This PI controller governs the AC SG output voltage. If the increased load induces voltage drop on DC-Link, the

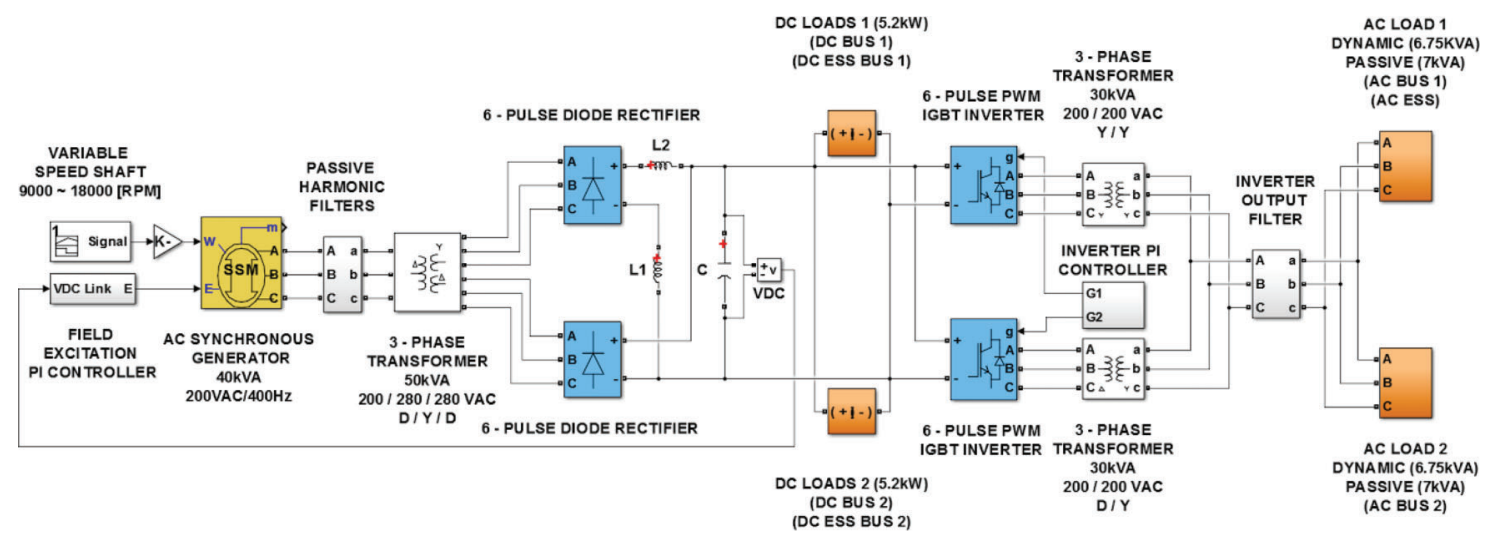

Figure 5. Proposed Embraer E190/195 VSCF DC-Link for AC-DC-AC power generation, conversion, and distribution. 
voltage of AC generator will increase to compensate for it. The proportional $K_{p}$ and the integral $K_{i}$ gains were tuned in order to obtain a satisfactory transient and steady-state performance (Nise, 2011). A schematic of AC SG field excitation governing using PI controller is illustrated in Figure 6. Consult Appendix $\mathrm{C}$ for more details on tuning of PI and PID controllers. Three-phase passive harmonic filters on AC SG output are depicted in Figure 7.

\section{Reference VDC}

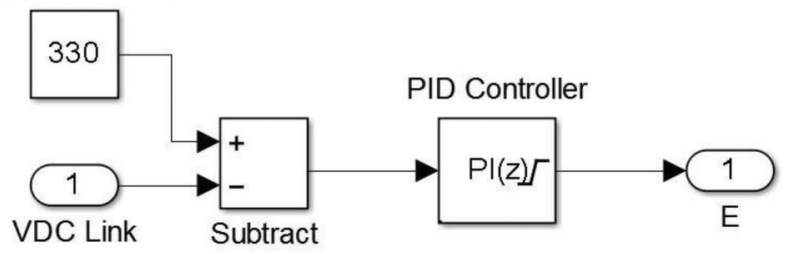

Figure 6. PI control of AC synchronous generator field excitation.
To achieve the required $28 \mathrm{VDC}$ for the DC bus in the E190, a closed-loop DC-DC Buck converter was designed. The DC-DC Buck converter steps down 330 VDC DC-Link voltage to 28 VDC using a dedicated PI controller to modulate the pulse (PWM) in the power switch (MOSFET used for that). A Simulink ${ }^{\circledR}$ schematic of PI control and Buck converter is shown in Figure 8.

For the two 6-pulse IGBT inverter bridges, the control was achieved using a PWM control block, which is governed by a dedicated PI control system. This block is a pre-designed control system available in Simulink ${ }^{\circledR}$. We only adjusted the desired output frequency $(400 \mathrm{~Hz})$, and PI-controller's $K_{p}$, and $K_{i}$ gains. The same control system governs the two IGBT inverters. In order to create a real 12-pulse inverter, $\mathrm{Y} / \mathrm{Y}$ and $\mathrm{D} / \mathrm{Y}$ transformers were introduced at inverter outputs creating a phase shift of 30 degrees between them, as illustrated in Figures 5 and 9.

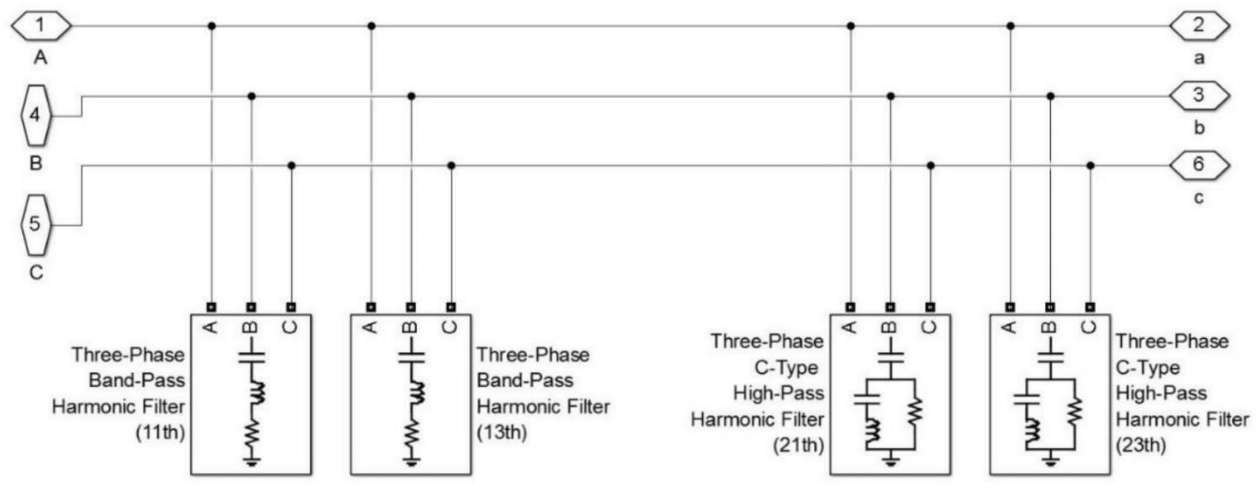

Figure 7. Generator output 3- $\phi$ passive harmonic filters.

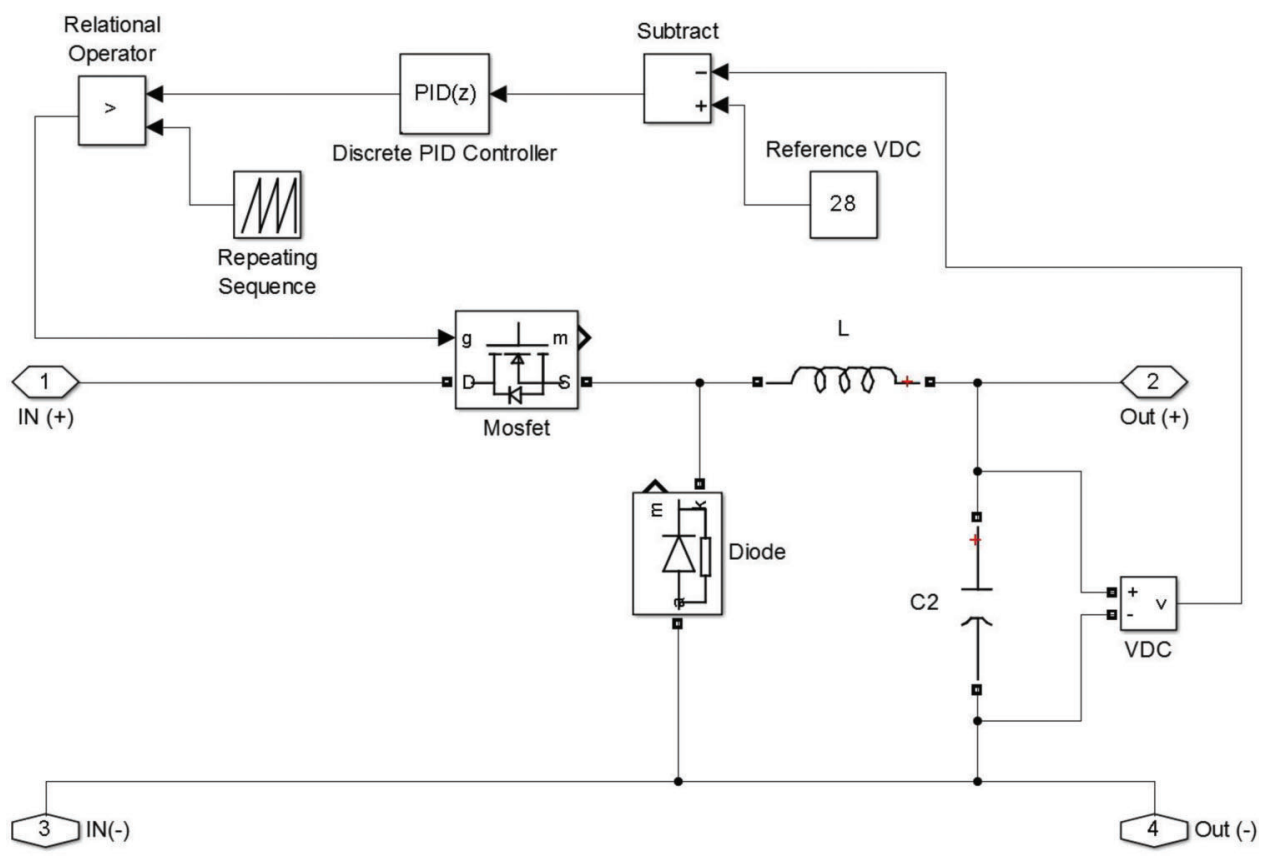

Figure 8. DC-DC Buck converter with PID control. 


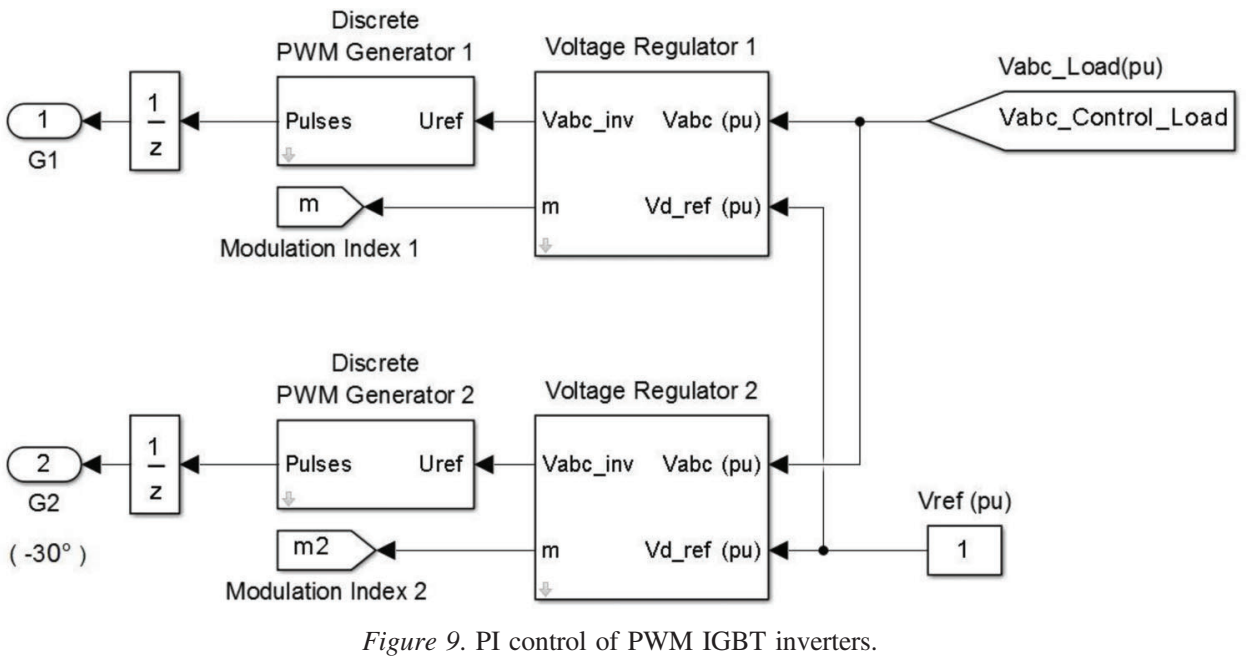

In order to reduce THDs below 5\% (on generator terminals and in the inverter's output), as the maximum recommended by MIL-STD-704F (DOD, 2008), passive low-pass (LP) RLC filters were implemented. Passive filters on AC SG output were already shown in Figure 7. Inverter output filters as implemented in Simulink ${ }^{\circledR}$ are shown in Figure 10. Passive filters have many advantages over active filters as described in Eid et al. (2010a). Passive filters are cheaper and one fewer active control circuit is required increasing system's reliability and robustness. Details on design of passive RC and RLC LP, bandpass (BP), and high-pass (HP) filters are presented in Appendix E. Single tuned filters for the $11^{\text {th }}$ and $13^{\text {th }}$ harmonic-order and the high-pass (HP) filters for the $23^{\text {rd }}$ and the $25^{\text {th }}$ harmonic order were implemented at generator terminals. Utilizing passive filters only we obtained significant reduction in $\mathrm{THD}_{\mathrm{v}}$ and $\mathrm{THD}_{\mathrm{i}}$. For the output of the inverter an RLC filter was used.

Passive DC loads were attached to the DC-Link using DC-DC Buck converter (Mohan et al., 2003, 2012) with constant 28 VDC and controlled by dedicated PID controller. Two DC loads were implemented (see Figure 5) to provide $5.2 \mathrm{~kW}$ to each DC bus (main and essential) for Channels 1 and 2 (see Figure 4). In normal operation, just one DC load will be fed by the DC-Link through the DC-DC Buck converter. The two DC loads represent about $26 \%$ of the total generator \#1 capacity (40 kVA).

Passive and dynamic AC loads were attached to the inverter output in order to simulate the conventional AC loads in existing E190 EPS design. Two equal passive load groups were designed. One for each channel and each group has three different loads. The three passive loads are rated at $2.5 \mathrm{kVA}, 3.5 \mathrm{kVA}$, and $1.0 \mathrm{kVA}$. The PF of these passive load groups is 0.85 in each and is in compliance with the MIL-STD-704F (DOD, 2008), which established $\mathrm{PF}=0.85$ as the minimum required. The two passive load groups will jointly activate only under scenario or case \#3 (failure of SG \#2). This represents abnormal EPS opera-

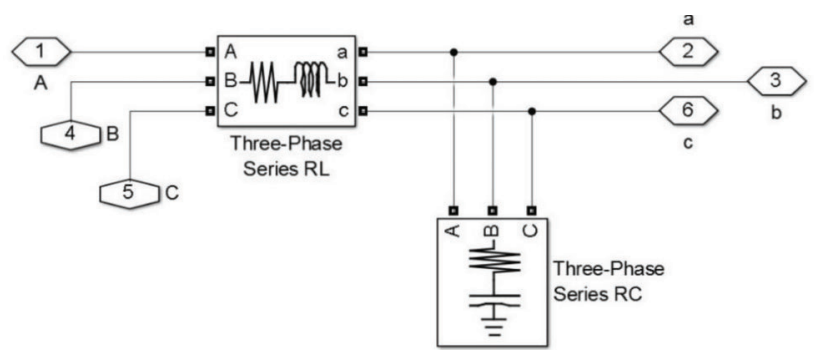

Figure 10. Inverter output 3- $\phi$ passive RLC filters.

tion and SG \#1 has to supply both channels \#1 and \#2. The two AC passive load groups represent $35 \%$ of the total generator \#1 capacity. For dynamic loads, two groups of AC motors, one for each channel, were used. Each channel supplies three different motor loads with different torque and power requirements. The rated apparent powers are $3 \mathrm{kVA}, 2.5 \mathrm{kVA}$, and $1.25 \mathrm{kVA}$. These two AC dynamic load groups represent $33.75 \%$ of the total AC generator SG \#1 capacity.

\section{Results and Discussion}

For a better understanding of how the possible future E190/195 DC-Link VSCF EPS functions during normal and abnormal situations, three different Simulink ${ }^{\circledR}$ simulations are presented. Transient accelerations from the E190/ 195 turbofan engine's speeds (idle to maximum thrust) were used. The turbofan's high-pressure (HP) spool RPM changes from about 9,000 to 18,000 RPM (idle to maximum RPM for GE CF34-10E). In the absence of relevant design information we assumed that the accessory (main) gearbox has a gear ratio of 1:1 for SGs. Accordingly the AC generator synchronous frequency varies from 300 to $600 \mathrm{~Hz}$ at the generator output. A particular simulation of extreme speed changes (e.g., go-around) is illustrated in Figure 11. The relationship between the rotor RPM and the frequency is given by Equation (1). The 3- $\phi$ AC SG has two pole-pairs, or four poles, per phase. All of the simulations 

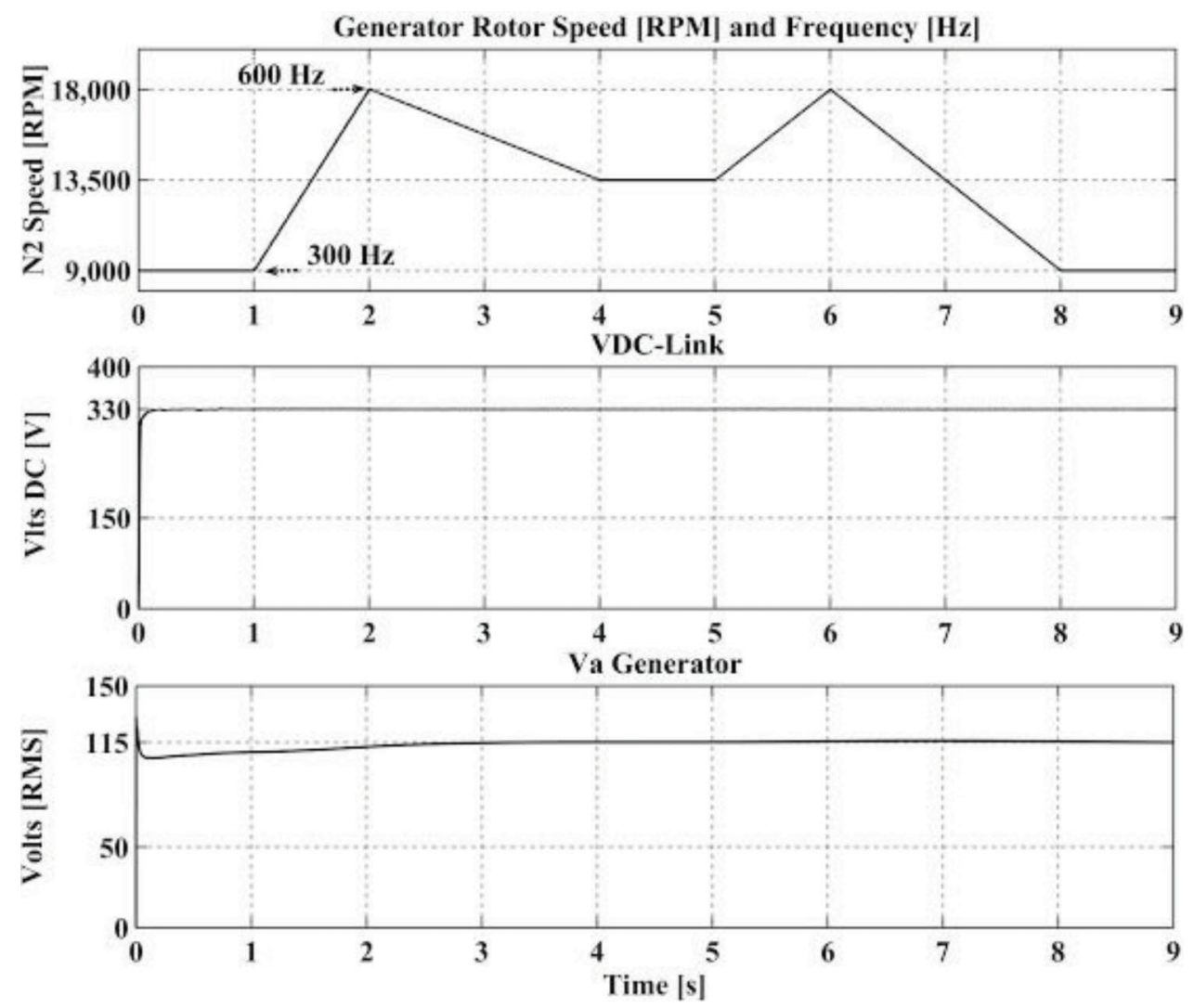

Figure 11. The increase in generator RPM and fundamental frequency with the turbofan speed increase.

Table 2

Channel 1 (40 kVA) supplying the entire system.

\begin{tabular}{cccccccc}
\hline Case \# & ICC & Start Time & DC(5.2 kW) & $\begin{array}{c}\text { Passive AC } \\
(\mathbf{7} \text { kVA })\end{array}$ & $\begin{array}{c}\text { Dynamic AC } \\
(\mathbf{6 . 7 5} \mathbf{k V A})\end{array}$ & $\begin{array}{c}\text { \% Channel } \\
(\mathbf{1 9} \text { kVA })\end{array}$ & $\begin{array}{c}\text { \% of the load } \\
(\mathbf{4 0} \mathbf{k V A})\end{array}$ \\
\hline 1 & $\begin{array}{r}\text { LICC or } \\
\text { RICC }\end{array}$ & $0.1 \mathrm{~s}$ & $\mathrm{x}$ & & & $27 \%$ & $13.00 \%$ \\
2 & $\begin{array}{c}\text { LICC or } \\
\text { RICC }\end{array}$ & $0.1 \mathrm{~s} / 0.2 \mathrm{~s}^{*}$ & $\mathrm{x}$ & $\mathrm{x}$ & $\mathrm{x}$ & $100 \%$ & $47.38 \%$ \\
\hline
\end{tabular}

*Start time for passive and dynamic AC loads.

were performed for the real-time interval of 0 to 9 seconds. Also DC-Link and SG RMS voltages are presented for reference. It was already shown with Equation (2) that inverter input voltage must be at least 330 VDC. To keep this voltage constant, a dedicated PI controller is used. Connecting loads and increasing frequency of SG $\left(\mathrm{N}_{2}\right.$ spool-up) causes initial drop and then increase in generator RMS voltage. DC-Link DC voltage remains constant at $330 \mathrm{~V}$. The purpose of this simulation was to estimate electrical system response under the largest stresses

The normal condition (scenario \#1) simulates the minimum load on the channel $\# 1$ and is rated at $5.2 \mathrm{KW}$ for one DC load group (see also Figure 4). The DC load will activate 0.1 seconds after simulation onset and will remain constant on the DC link for 9 seconds during SG frequency variations. This case was simulated to understand system behavior and dynamics at low reactive loads.
The scenario \#2 also involves simulation of the singlechannel normal electric operation (LICC or RICC). For this simulation passive and dynamic AC loads were added using asynchronous motors and RL loads. The AC dynamic and passive group \#1 will start 0.1 second after the DC load group \#1 activated or 0.2 seconds after simulation starts.

Safety regulations and design require that a single E190/ 195 AC generator must be capable of supplying the entire EPS at full demand without significant degradation in the case of failure of the other AC generating power unit (EMBRAER 190 Manual, p. 1551). In that case, the tie connectors BTC and DCTC will activate and the electrical power from the operating SG \#1 will flow to busses which lost respective generator supply SG \#2 (see Figure 12). An SG \#2 failure scenario \#3 simulates abnormal electrical system condition. In this case, operating $\mathrm{AC}$ generator will 


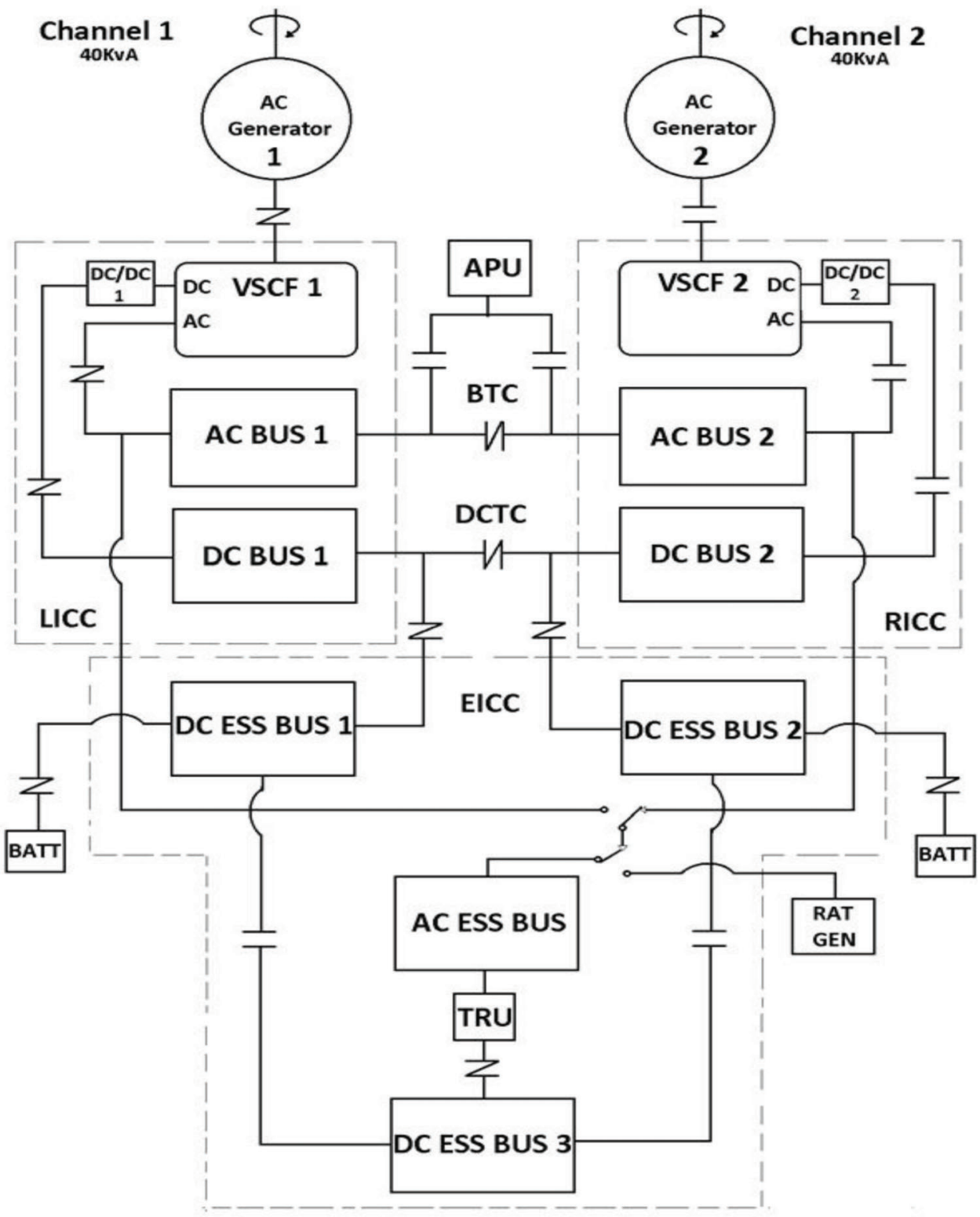

Figure 12. Electrical network in case \#3 (abnormal ops) for the new proposed E190/195 EPS.

Table 3

Channel 1 (40 kVA) supplying the entire system. AC generator 2 failed.

\begin{tabular}{cccccccc}
\hline Case $\#$ & ICC & Start Time & DC(5.2 kW) & Passive AC(7 kVA) & $\begin{array}{c}\text { Dynamic AC } \\
(\mathbf{6 . 7 5} \text { kVA })\end{array}$ & $\begin{array}{c}\text { \% Channel } \\
(\mathbf{1 9} \text { kVA) }\end{array}$ & $\begin{array}{c}\text { \% of the load } \\
(\mathbf{4 0} \text { kVA })\end{array}$ \\
\hline \multirow{2}{*}{3} & LICC & $0.1 \mathrm{~s} / 0.2 \mathrm{~s}^{*}$ & $\mathrm{x}$ & $\mathrm{x}$ & $\mathrm{x}$ & $100 \%$ & $47.38 \%$ \\
& RICC & $0.4 \mathrm{~s} / 0.5 \mathrm{~s}^{*}$ & $\mathrm{x}$ & $\mathrm{x}$ & $\mathrm{x}$ & $100 \%$ & $47.38 \%$ \\
& & & & & & $94.76 \%$ \\
\hline
\end{tabular}

\footnotetext{
* Start time for Passive and Dynamic AC loads.
}

work at almost full capacity (95\%) due to existing AC (dynamic and passive) and DC load groups. We simulate normal operating condition from 0 to $0.3 \mathrm{~s}$ (case \#2), sudden SG \#2 failure, and at the $0.4 \mathrm{~s}$ instant, the second DC loads group will be connected. The second group of AC loads is connected at $0.5 \mathrm{~s}$ instant as summarized in Table 3 .

\section{Simulation Analysis}

The $\mathrm{PF}$ at the generator terminals was measured in scenario \#1. The PF drops as the frequency increases as shown in Figure 13. However, the drop of PF was not significant due to low reactive loads. The voltage and 


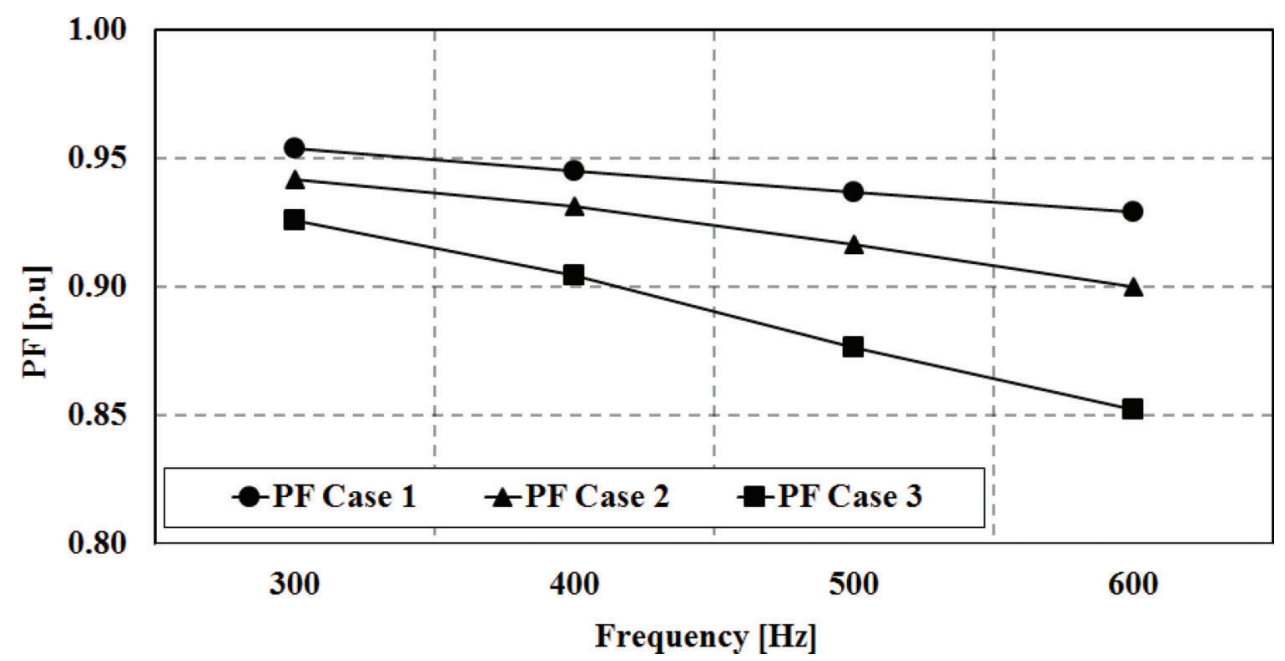

Figure 13. PFs for all three simulated cases (scenarios) at generator terminals.

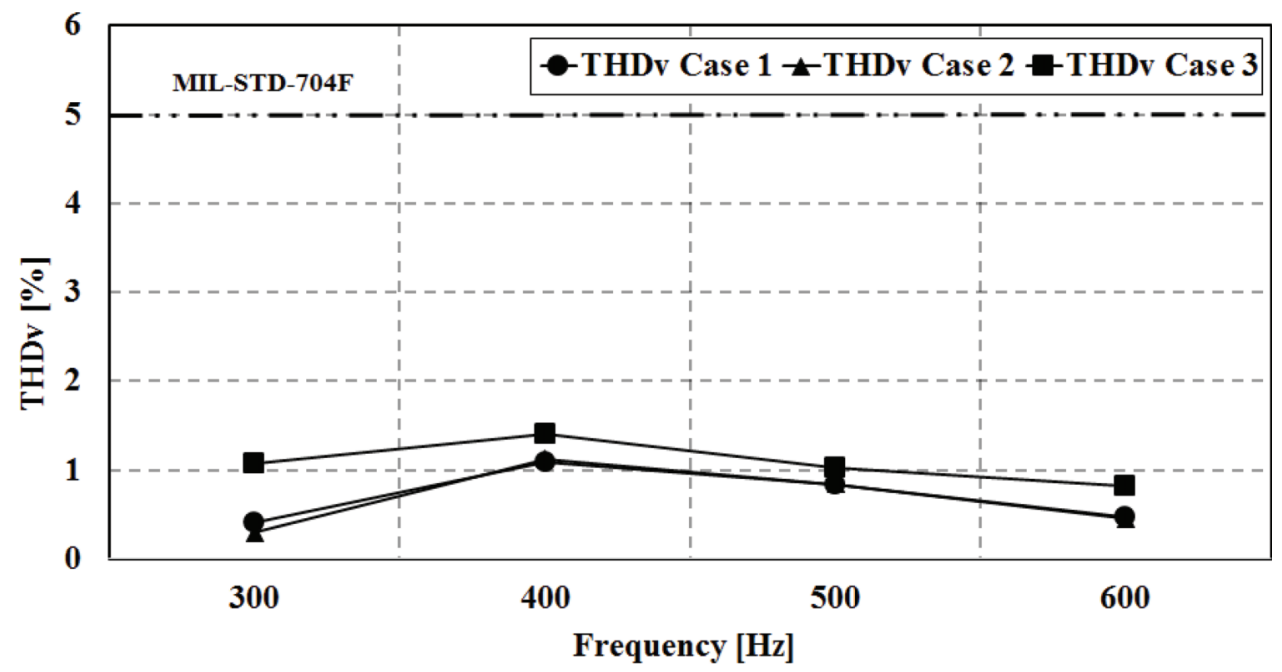

Figure 14. $\mathrm{THD}_{\mathrm{v}}$ at generator terminals.

current THDs were measured at the generator terminals and at the output of the inverter where the AC loads were attached. The results for $\mathrm{THD}_{\mathrm{v}}$ and $\mathrm{THD}_{\mathrm{i}}$ are shown in Figures 14 and 15, respectively. Theoretical details on PF definition and calculations are given in Appendix A. The reactive power $(\mathrm{Q})$ is measured in Volt-Ampere-Reactive (VAR) and is proportional to AC frequency implying that increasing the frequency the reactive power will increase as well, lagging or leading the voltage. In case $\# 1$, where low reactive elements are connected to the system and the real power $(\mathrm{P}$ in $\mathrm{W})$ remains constant, the $\mathrm{PF}(\mathrm{PF}=\mathrm{P} / \mathrm{S})$ exhibits very shallow decrease with increasing frequency. On the other hand, in cases \#2 and \#3, where relatively high reactive elements (asynchronous motors and passive RL loads) are connected, the PF exhibits more significant drop with increasing frequency. Transformer voltage regulation (200/280/280) and THD filters were utilized to improve PF.
In all cases (scenarios), the highest PF consistently occurs at the minimum SG frequency of $300 \mathrm{~Hz}$. The lowest PF of 0.85 was experienced in case \#3 at the highest frequency of $600 \mathrm{~Hz}$. The AC passive loads have the $\mathrm{PF}$ of 0.85 and the $\mathrm{AC}$ dynamic load of 0.97 in all simulated scenarios. Thus the total PF of AC loads is around 0.91. This PF contributes to the decrease of PF on SG terminals. High THD can cause high temperatures in the core of the generators and transformers and it can cause interference in transmission lines because of the possible resonance problem. The THD can be alleviated by active or passive filter systems. Passive filters to reduce voltage $\left(\mathrm{THD}_{\mathrm{v}}\right)$ and current $\left(\mathrm{THD}_{\mathrm{i}}\right)$ harmonics were implemented here (see Appendix E for more details). The MIL-STD704F defines acceptable THD as being less than 5\%. The maximum value of $\mathrm{THD}_{\mathrm{v}}$ was only $1.4 \%$ for case $\# 3$ as seen in Figure 14. The $\mathrm{THD}_{\mathrm{i}}$ (Figure 15) showed high frequency and load sensitivity. As the load and 


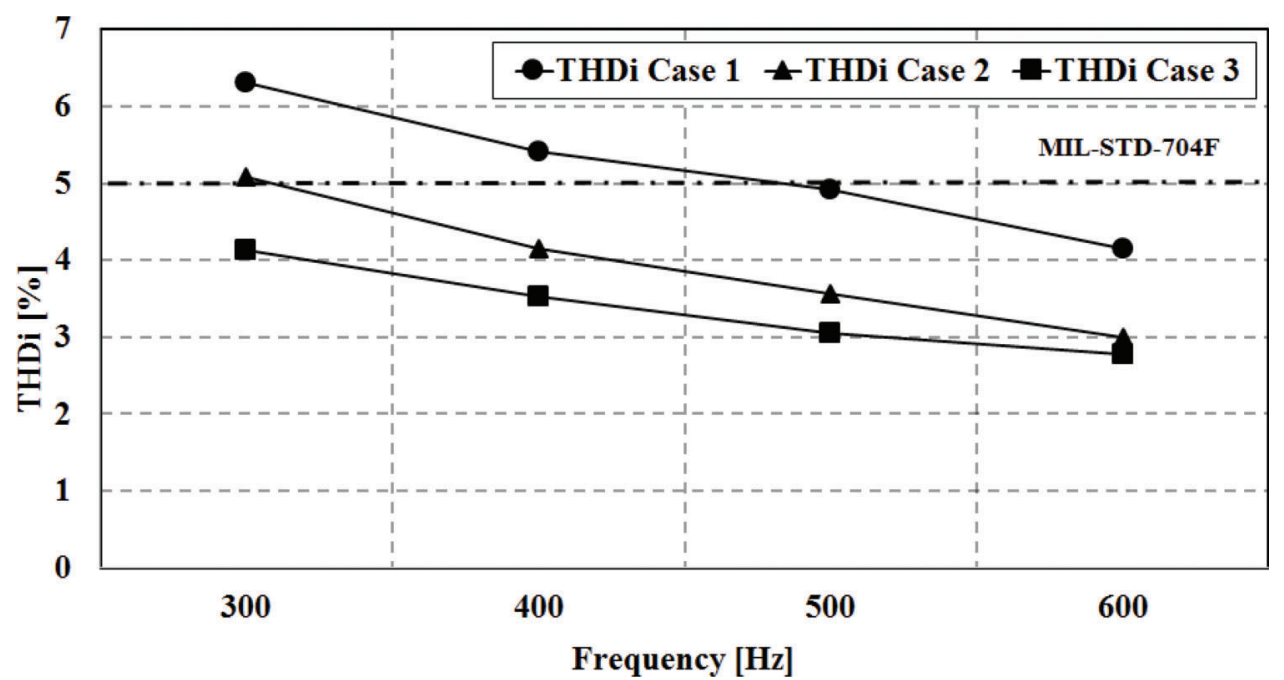

Figure 15. $\mathrm{THD}_{\mathrm{i}}$ at generator terminals.
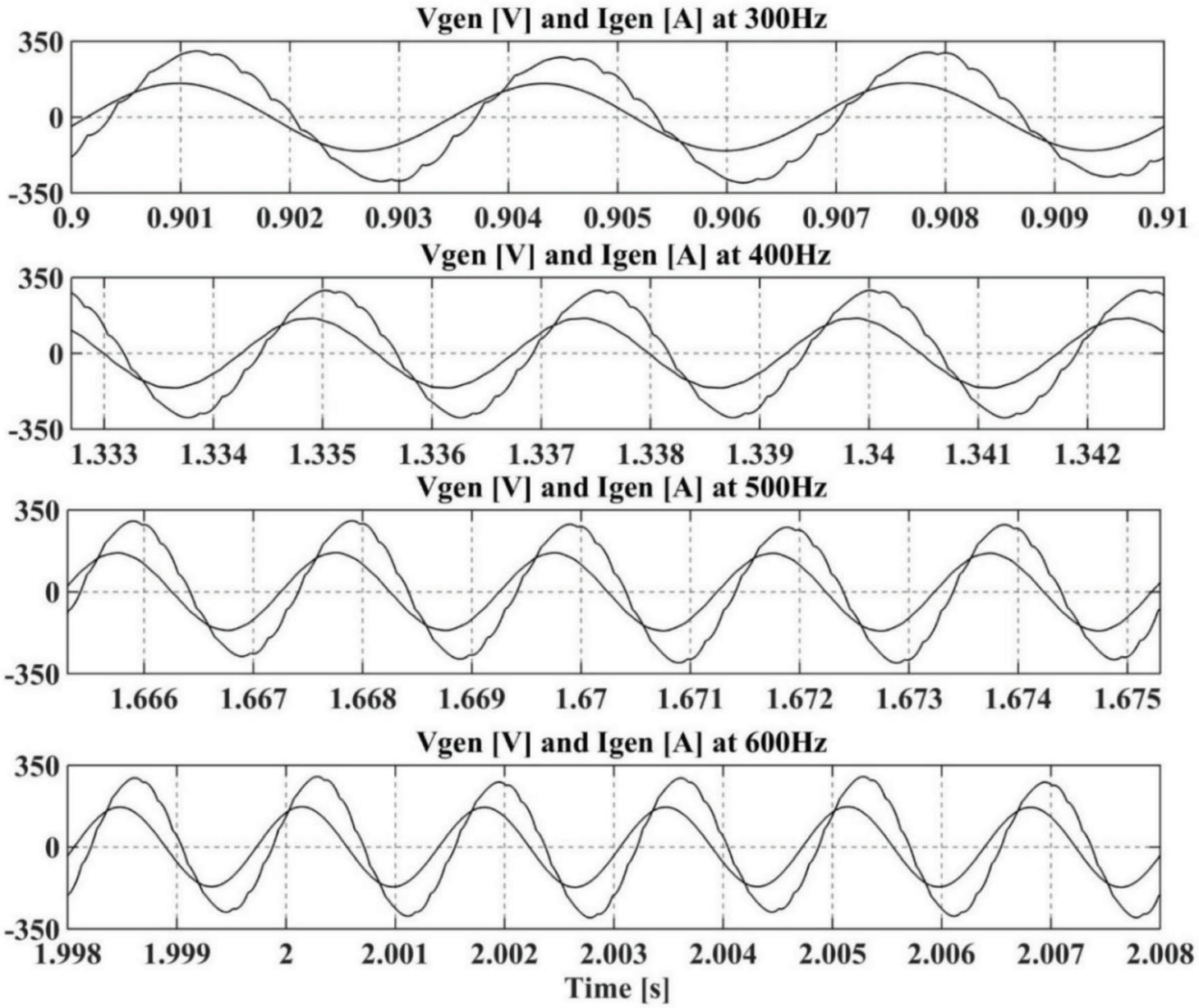

Figure 16. Shift between line voltages and currents on generator terminals for $\mathrm{PF}<1$ at four discrete frequencies $(300,400,500$, and $600 \mathrm{~Hz})$.

frequency increased, $\mathrm{THD}_{\mathrm{i}}$ decreased significantly. Part of the reason is the use of passive RLC filters at generator terminals intended to reduce the main harmonics $\left(11^{\text {th }}\right.$ and $13^{\text {th }}$, and $23^{\text {rd }}$ and $\left.25^{\text {th }}\right)$. A phase shift between the current and voltage at four discrete generator frequencies is shown in Figure 16. 

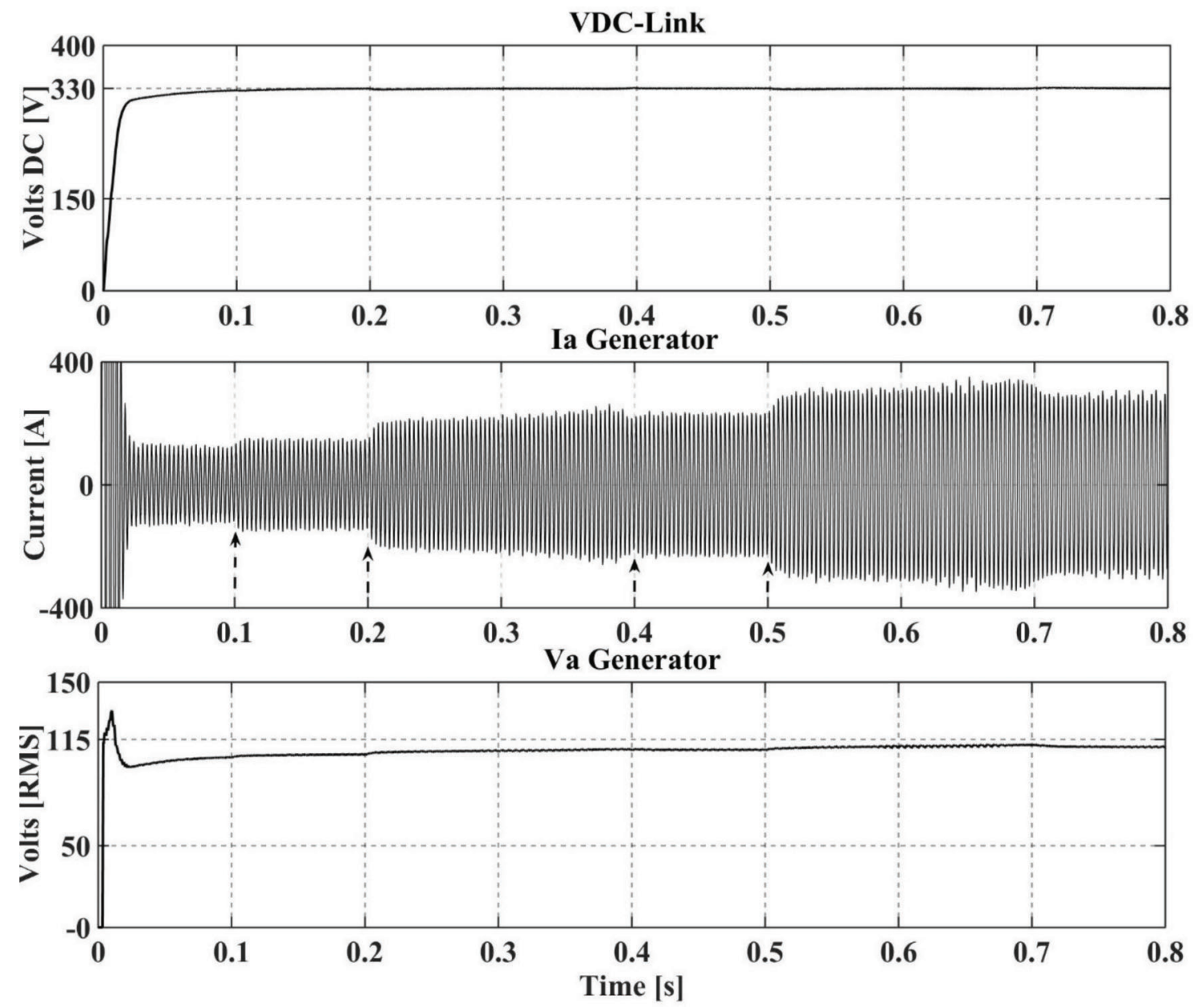

Figure 17. Variation of frequency and voltage transient at generator terminal for case 3.

Figure 17 shows the variation of SG output current and voltage as DC (0.1 and 0.4s) and AC (0.2 and 0.5s) loads are connected. A constant $330 \mathrm{VDC}$ is maintained in DC-Link thanks to field excitation PI controller which compensates for the additional loads by increasing the generator output RMS voltage. These SG output current jumps are clearly noticeable at 0.2 and 0.5 seconds instants where the generator output RMS voltage somewhat increases.

The temporal sample (window) of the load voltage is shown in Figure 18. Sudden passive and dynamic load jumps at given instants cause voltage distortions. At the time of $0.2 \mathrm{~s}$, the AC load group \#1 (passive and dynamic loads) and at $0.5 \mathrm{~s}$ the AC group \#2 is connected to the electric network. Those events cause momentary voltage drops. Nevertheless, the voltage spikes and transients are still in compliance with the MIL-STD-704F (DOD, 2008). The load input voltage history during the entire simulation duration can be observed in the Figure 19. Despite voltage and frequency variations at the generator terminals, the AC loads input voltage and frequency remained constant after AC loads have been activated.

A constant DC-Link $330 \mathrm{~V}$ input, Vab output before filtering, Vab after filtering, and the changing modulation index are all shown in Figure 20 for one (out of two) 6-step IGBT inverter. The modulation index has to compensate for the connection of AC loads at times of 0.2 and $0.5 \mathrm{~s}$. The inverter output has significant harmonics distortion due to IGBT switching. Hence, a very common and simple passive RLC filter for the inverter output was adopted. A $\mathrm{THD}_{\mathrm{v}}$ reduction is quite noticeable in Figure 20.

A 12-step inverter output before (or without) and after the filter action is shown in Figure 21. The presence of higher harmonics before filtering is obvious. It also demonstrates the importance of filters in practical switching circuits. The temporal and spectral representation of signal/ waveforms of currents and voltages for the scenario \#2 at generator frequency of $300 \mathrm{~Hz}$ where analyzed and presented in Figure 22. Fast Fourier Transform (FFT) algorithm was used to obtain discrete frequency spectrum. THD was calculated for both cases of currents and voltages. Current waveforms are on the left and voltage signals are on the right. Using FFT and normalizing harmonic content as described in Appendix B, the values of $2.43 \%$ for $\mathrm{THD}_{\mathrm{i}}$ and $7.58 \%$ for $\mathrm{THD}_{\mathrm{v}}$ were obtained. THD for current or $\mathrm{THD}_{\mathrm{i}}$ is within $5 \%$ acceptable magnitude, but voltage THD or $\mathrm{THD}_{\mathrm{v}}$ is $2.58 \%$ higher than the maximum standard 


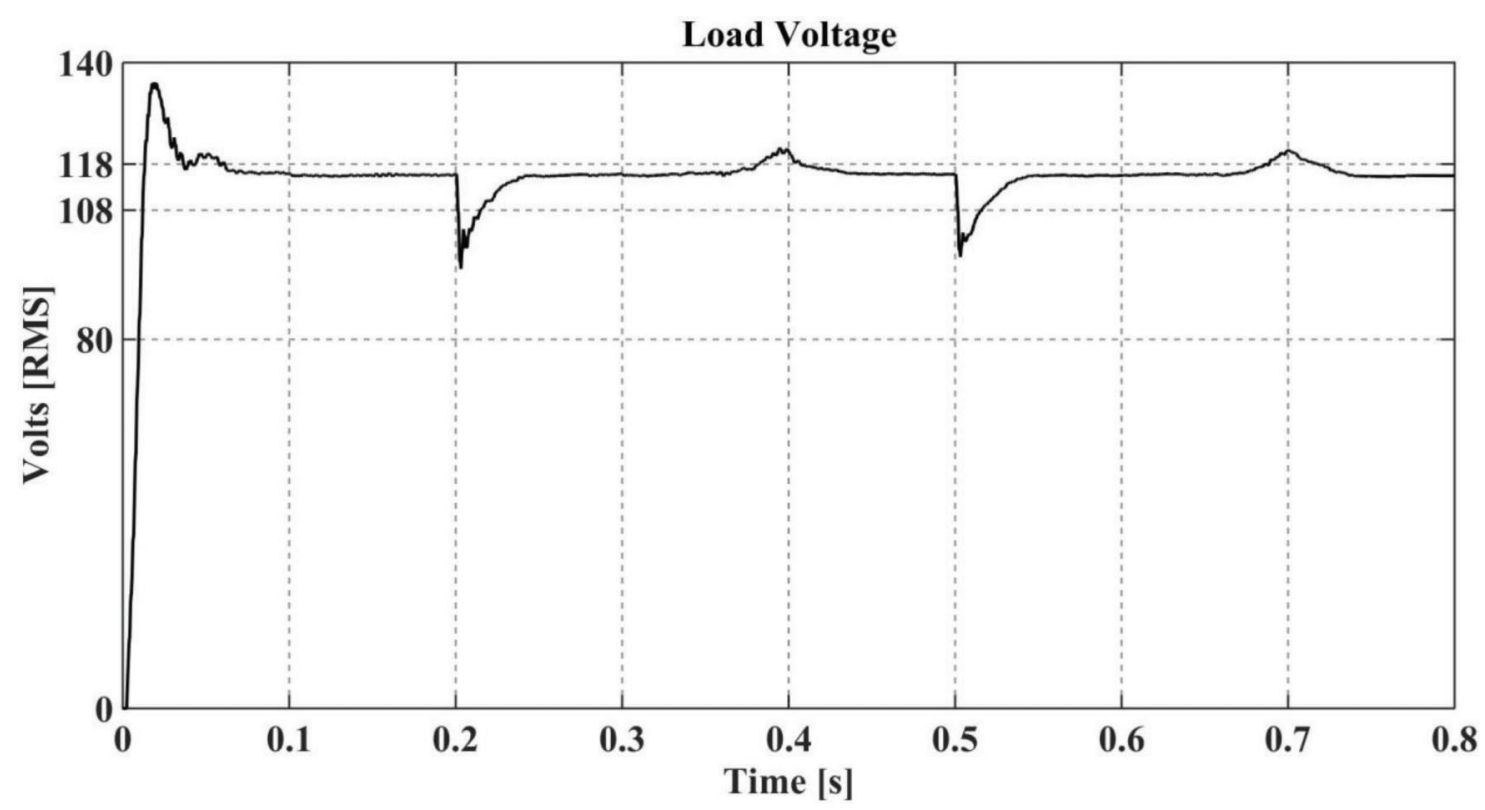

Figure 18. Initial load voltage spikes and transients.

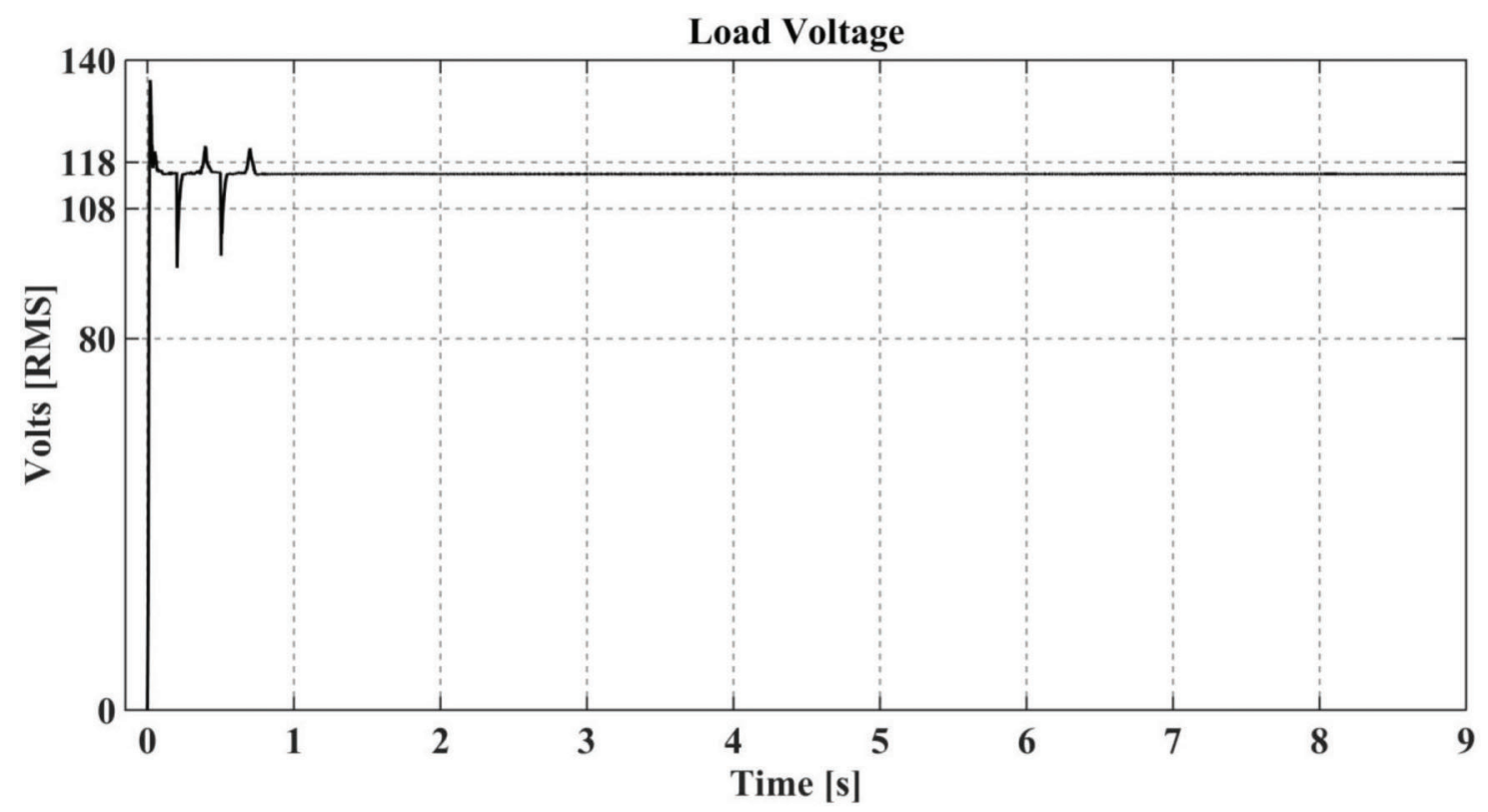

Figure 19. Load voltage spikes and transients for the entire simulation period.

recommendation of 5\% (DOD, 2008; IEEE, 1992). Thus filters are needed.

After the addition of harmonic passive filters at generator terminals, the values of $\mathrm{THD}_{\mathrm{i}}$ (Figure 23 left) actually increased to $4.14 \%$, but are still acceptable and below the $5 \%$ limit. On the other hand, the voltage THD significantly dropped from the original $7.58 \%$ to just $1.08 \%$ (Figure 23 right). Such tradeoff is acceptable especially when one considers that only simple analog passive filters are used on SG terminals. Unfortunately, the situation gets worse with higher SG frequencies $(400-600 \mathrm{~Hz})$ and the power quality is reduced. Thus, active filters may be required in the future to minimize THDs for the entire SG frequency range. Similar effort was done by Eid et al. (2010a).

A conceptual design, mathematical model, and simulation of an AC-DC-AC DC-Link VSCF EPS for an Embraer E190/195 airplane were all accomplished in this applied research effort. The main objective was to obtain a constant frequency of $400 \mathrm{~Hz}$ and the quality electrical power at 115 VAC with acceptable PFs and THDs. For the most part that was achieved. Current production models of E190/195 use conventional IDGs. The goal here was to replace IDG with 

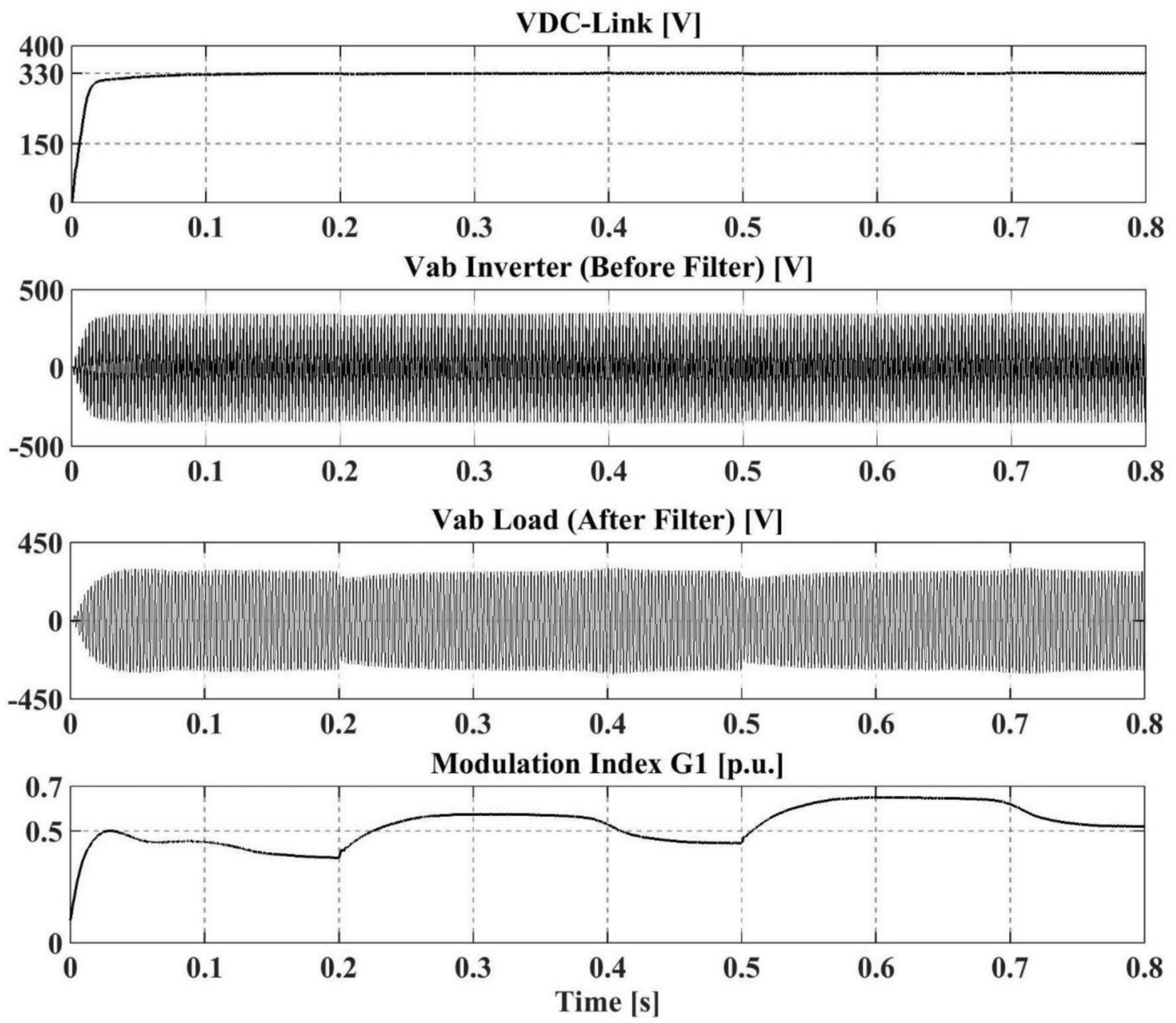

Figure 20. The 115VAC of inverter output.
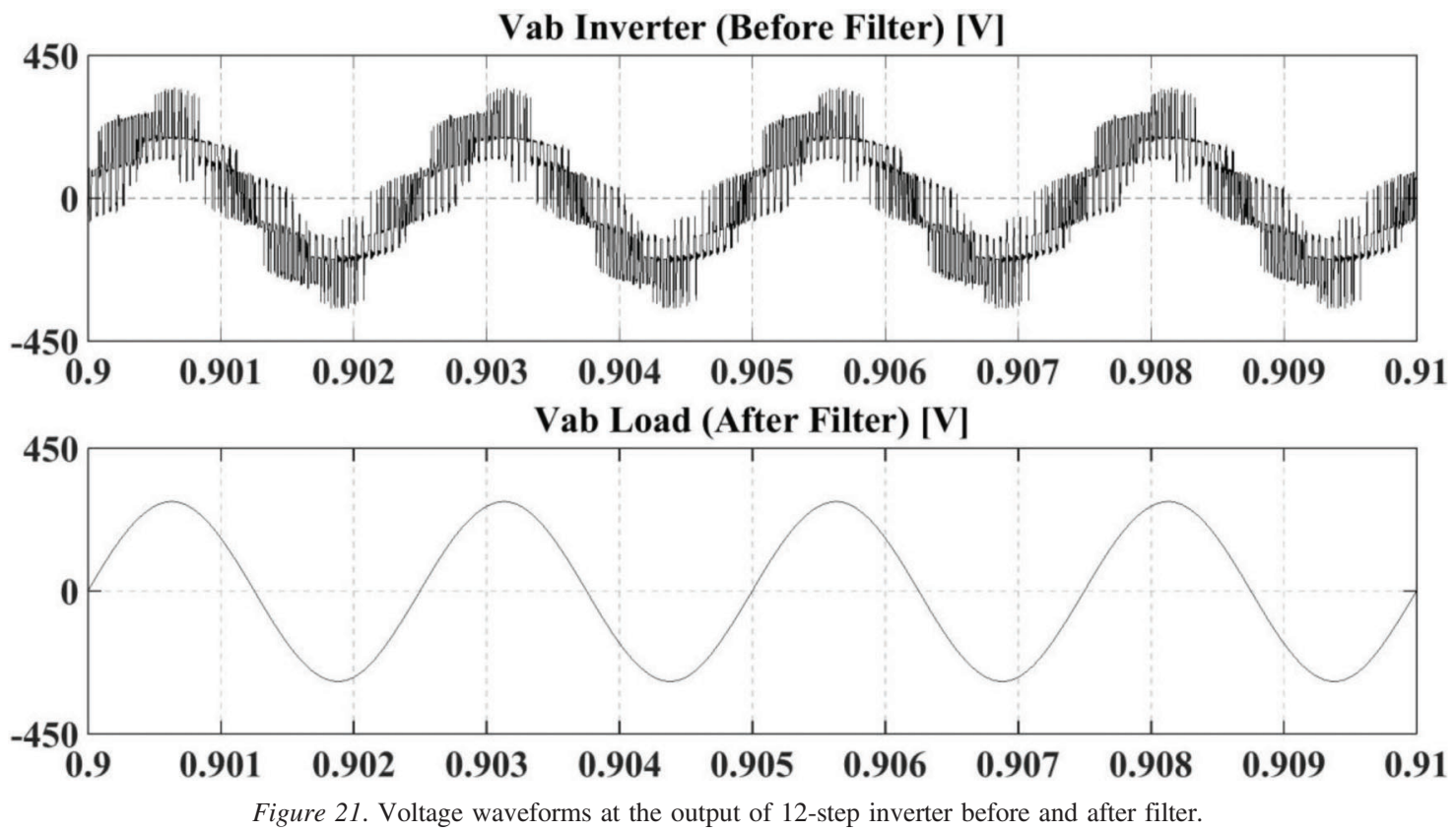

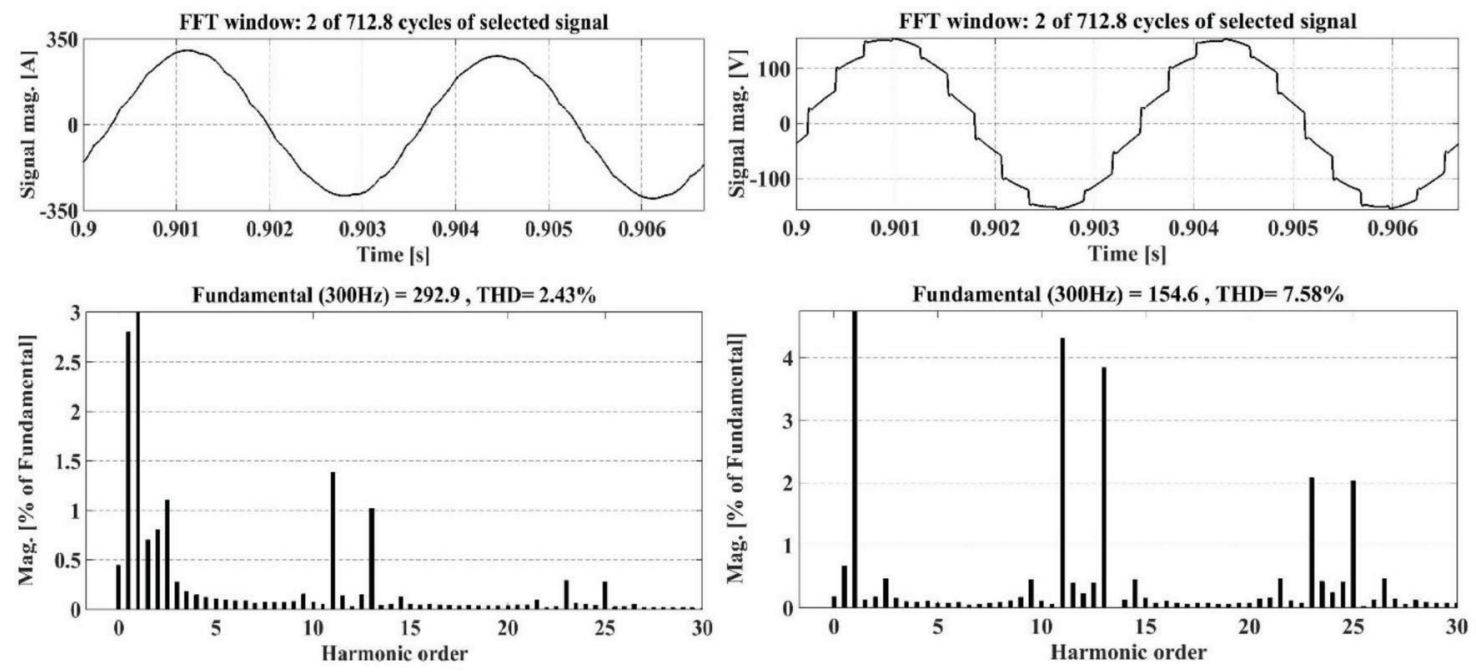

Figure 22. Current and voltage waveforms and respective spectral representations at SG terminals before filtering.
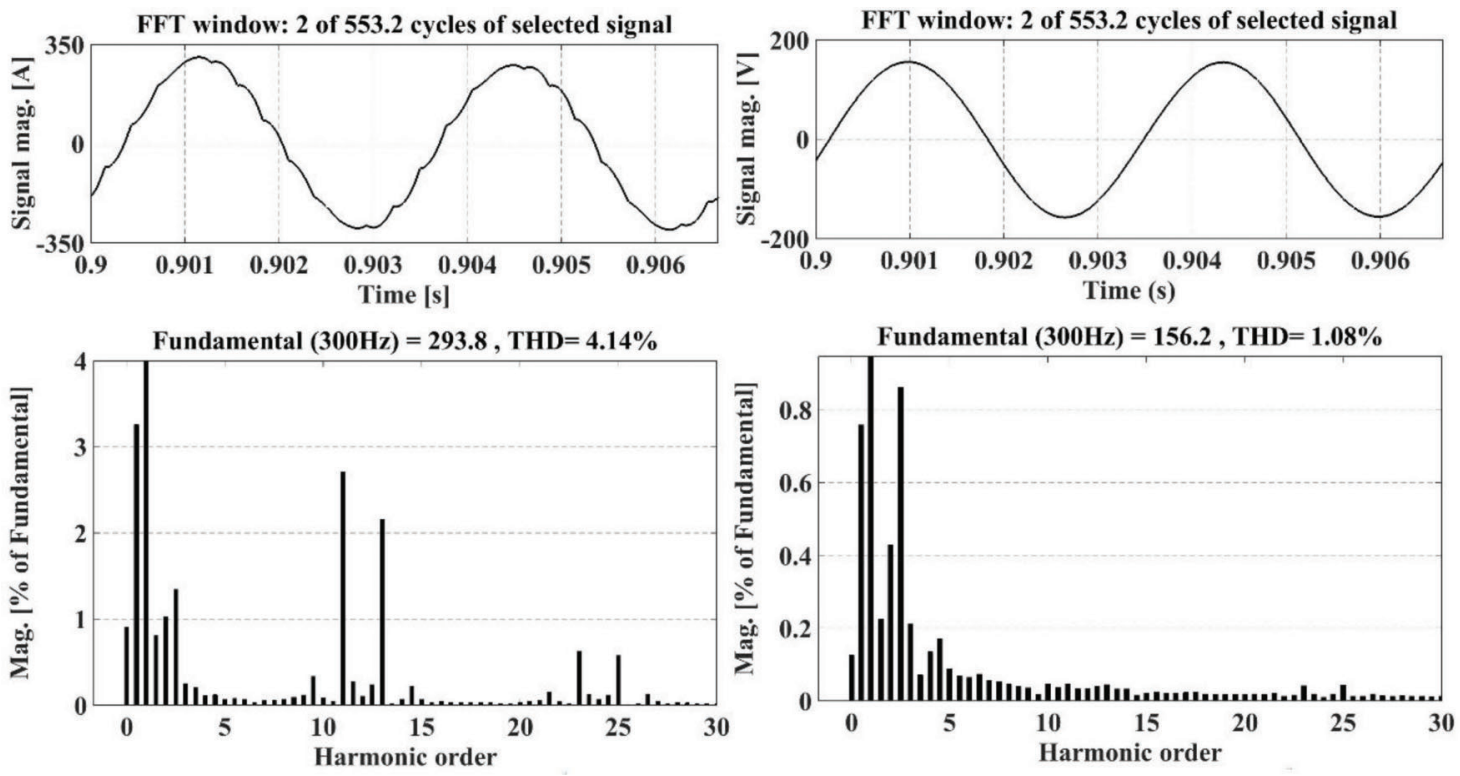

Figure 23. Current and voltage waveforms and respective spectral representations at SG terminals after filtering.

a solid-state power electronics which offers higher reliability and better control. The frequency of the prime source (AC synchronous generator) varied between $300 \mathrm{~Hz}$ and $600 \mathrm{~Hz}$ and proportionally to the $\mathrm{N}_{2}$ or high-pressure (HP) spool to which it was mechanically geared. Simulations of normal operation with variable AC/DC load and the worst-case abnormal operation (loss of one $\mathrm{SG}$ ) were performed. The power quality was demonstrated using PFs and THDs and compared to military standard MIL-STD-704F and IEEE-Std. 519 requirements. The 12-step IGBT inverter passive filter worked very well keeping the voltage and current THDs below 1\%. On the other hand, the passive filter on the SG terminals did not perform as hoped in the entire operational envelope. PF still needs some improvements although passive filters helped improve it. It was noticed that the PF increases slightly when the first transformer of the rectifier has the voltage output higher than the input. Simultaneously, the $\mathrm{THD}_{\mathrm{i}}$ increased when the output transformer voltage was higher than the input. Thus the values of $200 \mathrm{~V} / 280 \mathrm{~V} / 280 \mathrm{~V}$ (D-Y-D) where adopted for the first 3- $\phi$ transformer (see also Figure 5). Although not currently used in production aircraft, we included a Buck converter in DC-Link which also delivers 270 VDC (in addition to 28 VDC) as an emerging new standard in aircraft EPSs.

More work is envisioned to refine the model, perform simulations, and remove some assumptions made regarding the ideal switching dynamics. Active filters may also be implemented in some future designs to improve THD on generator terminals. More work will be conducted to improve the PF as much as possible without incurring too high expenses and needlessly increasing system weight. 
In future work, rectifiers and inverters without transformers will be examined in order to further reduce weight of this system. Alternatively, a 6-step system which does not need transformers for phase shifting can be adopted as well. For the 6-step system, a harmonic reduction system must be well designed since we have lower harmonics in the generator terminals than for the 12-step system. Direct comparison of weights, reliability, and cost between the existing traditional IDG-based EPS and the possible future VSCF DC-Link system will be made in subsequent publications.

\section{Conclusions}

We have successfully modeled an AC/DC/AC DC-Link VSCF electrical system for an E-190/195 twin-engine medium-range production jet. VF AC is generated at each engine-driven AC compound-SG with controlled field excitation. This VF AC power is then converted into 330/ 270/28 VDC using DC-link's 12-pulse rectifier bridge employing uncontrolled power diodes. Buck converter is used step down voltages to 270 and 28 VDC. About 30-50\% of the total electric power is used for various DC loads. Current E190/195 EPS design does not utilize 270 VDC, but we provided it here as it is becoming, de-facto, new standard. The generator voltage output is controlled by PI controller and the rectifier output is refined using passive low-pass filter. The PI controller was tuned according to continuouscycle tuning method. The remaining DC power then enters a 12-step IGBTs inverter bank using carrier-based $100 \mathrm{kHz}$ bipolar triangular carrier-based PWM. Passive low- and band-pass passive filters are used to produce clean low-THD CF $400 \mathrm{~Hz}, 115 / 200 \mathrm{VAC}, 40 \mathrm{kVA}$ power per each generator. AC synchronous generators can be overloaded momentarily without serious side effects. The PF exceeded 0.85 with mostly inductive lagging AC loads. Inverter PI controllers have been tuned to provide required waveforms in terms of quality and applicable standards. Power and control systems are isolated. Steady-state and transient simulation analyses have been performed. During ramp transient where the engine power is rapidly increased from idle to maximum thrust, the VF changes from about 300 to $600 \mathrm{~Hz}$ requiring the VSCF system to maintain no-break $115 \pm 5$ VAC and $400 \pm 2 \mathrm{~Hz}$. Such simulations resulted in power quality, PF, and THD to be for the most part conforming to the MIL-STD-704F and the IEEE Std. 519 standards. Further power quality and system safety and reliability improvements of the E190/195 EPS preliminary design will be presented in subsequent articles.

\section{Acknowledgement}

Eduardo Francis Carvalho Freitas would like to express his gratitude for financial support for his continuing education at Minnesota State University, Mankato from August
2014 until December 2015. This work was conducted with scholarship supported by the International Cooperation Program CAPES at the Minnesota State University, Mankato, financed by CAPES - Brazilian Federal Agency for Support and Evaluation of Graduate Education within the Ministry of Education of Brazil.

\section{References}

Abdel-Fadil, R., Eid, A., \& Abdel-Salam, M. (2013). Electrical distribution power systems of modern civil aircrafts. $2^{\text {nd }}$ International Conference on Energy Systems and Technologies, 18-21 February, Cairo, Egypt, 201-210.

Abdel-Hafez, A. (2012). Power generation and distribution system for more electric aircraft-A review. In R. Agarwal, (Ed.), Recent advances in aircraft technology. Rijeka, Croatia: InTech Europe.

Abdel-Hafez, A., \& Forsyth, A. J. (2009). A Review of More-Electric Aircraft. 13th International Conference on Aerospace Sciences \& Aviation Technology, ASAT-13, Paper: ASAT-13-EP-01, May 26-28, 2009, Military Technical College, Kobry Elkobbah, Cairo, Egypt.

Abramowitz, M., Stegun, I. A. (1984). Handbook of mathematical functions (abridged edition). Frankfurt (am Main), Germany: Verlag Harri Deutsch.

Almaktoof, A. M., Raji, A. K., \& Kahn, M. T. E. (2014). Modelling and simulation of three-phase voltage source inverter using a model predictive current control. International Journal of Innovation, Management and Technology, 5(1), 9-13. https://doi.org/10.7763/IJIMT.2014.V5.477

Andrade, L., \& Tenning, C. (1992, July). Design of the Boeing 777 electrical systems. IEEE AES Magazine, 4-11.

Aström, K. J., \& Wittenmark, B. (2008). Adaptive control ( $2^{\text {nd }}$ ed.). Mineola, NY: Dover.

Aström, K. J., \& Wittenmark, B. (2011). Computer controlled systems: Theory and design ( $3^{\text {rd }}$ ed.). Mineola, NY: Dover.

Bell, D. A. (1981). Solid state pulse circuits ( $2^{\text {nd }}$ ed.). Reston, VA: Reston Publishing Company.

Bose, B. K. (2002). Modern power electronics and AC drives. Upper Saddle River, NJ: Prentice Hall.

Daidzic, N. E. (2012, March). FADEC advances allow better engine performance. Professional Pilot, 46(3), 78-82.

Davies, M. (Ed.) (2003). The standard handbook for aeronautical and astronomical engineers. New York: McGraw-Hill.

Eid, A., El-Kishky, H., Abdel-Salam, M., \& El-Mohandes, T. (2010a). On power quality of variable-speed-constant-frequency aircraft electric power systems. IEEE Transactions on Power Delivery, 25(1), 55-65. https://doi.org/10.1109/TPWRD.2009.2031672

Eid, A., El-Kishky, H., Abdel-Salam, M., \& El-Mohandes, T. (2010b). Power quality investigations of VSCF aircraft electric power systems. $42^{\text {nd }}$ South Eastern Symposium on System Theory (SSST 2010), Tyler, TX, USA, March 7-9, 171-176. https://doi.org/10.1109/ssst. 2010.5442840

El-Kishky, H., Ibrahimi, H., Abu Dakka, M., Eid, A., \& Abdel-Akher, M. (2011). Modeling and characterization of VSCF aircraft electric power systems with nonlinear loading. 2011 IEEE Pulsed Power Conference (PPC), 1482-1485, 19-23 June 2011, Chicago, IL, USA. http://doi.org/ 10.1109/PPC.2011.6191668

European Aviation Safety Agency. (EASA) (2007). Certification specifications for large aeroplanes CS-25 (Amendment 3, 19 September). Cologne, Germany: Author.

Empresa Brasileira de Aeronáutica S.A. (Embraer) (2010). Embraer 190 (AOM-1502-017, Revision 4). São José dos Campos, Brazil: Author.

Empresa Brasileira de Aeronáutica S.A. (Embraer) (2015). Embraer 190/ 195: Aircraft maintenance manual (24-00-00). São José dos Campos, Brazil: Author.

Fink, D. G., \& Christiansen, A. (Eds.) (1989). Electronics engineers' handbook ( $3^{\text {rd }}$ ed.). New York: McGraw-Hill. 
Fitzgerald, A. E., Kingsley, C. Jr., \& Umans, S. D. (2003). Electric machinery $\left(6^{\text {th }}\right.$ ed.). New York: McGraw-Hill.

Gong, G., Heldwein, M. L., Drofenik, U., Miniböck, J., Mino, K., \& Kolar J. W. (2005). Comparative evaluation of three-phase high-power-factor AC-DC converter concepts for application in future more electric aircraft. IEEE Transactions on Industrial Electronics, 52(3), 727-737. http://doi.org/10.1109/TIE.2005.843957

Gottlieb, I. M. (1994). Electric motors and control techniques ( $2^{\text {nd }}$ ed.). New York: McGraw-Hill.

Grigsby, L. L. (Ed.) (2007). Power systems. Boca Raton, FL: CRC Press/ Taylor \& Francis.

Hamming, R. W. (1998). Digital filters ( $3^{\text {rd }}$ ed.). Mineola, NY: Dover.

Hart, D. W. (2011). Power electronics. New York: McGraw-Hill.

Holtz, J. (1994). Pulsewidth modulation for electronic power conversion. Proceedings of the IEEE, 82(8), 1194-1214. https://doi.org/10.1109/5. 301684

Institute of Electrical and Electronics Engineers (IEEE). (1992). Recommended practices and requirements for harmonic control in electrical power systems (ANSI/IEEE Std. 519). Retrieved from http:// standards.ieee.org/

Jadric, I. (1998). Modeling and control of a synchronous generator with electronic load (Master's thesis, Virginia Polytechnic Institute and State University). Blacksburg, Virginia: Author.

Jeppesen. (2007). Electrics (JAA ATPL Training Ed. 2 JAR Ref 0121 02). Neu-Isenburg, Germany: Author.

Karris, S. T. (2008). Introduction to SIMULINK ${ }^{\circledR}$ with engineering applications ( $2^{\text {nd }}$ ed.). Fremont, CA: Orchard Publications.

Khaburi, D. A., \& Nazempour, A. (2012). Design and simulation of a PWM rectifier connected to a PM generator of micro turbine unit. Scientia Iranica, 19(3), 820-828.

Kilian, C. T. (2006). Modern control technology ( $3^{\text {rd }}$ ed.). Clifton Park, NY: Delmar.

Kirk, D. E. (2004). Optimal control theory: An introduction. Mineola, NY: Dover.

Luo, F. L., \& Ye, H. (2010). Power electronics: Advanced conversion technologies. Boca Raton, FL: CRC Press/Taylor \& Francis.

Malinowski, M., Milczarek, A., Kot, R., Goryca, Z., \& Szuster, J T., (2015, September). Optimized energy conversion systems for small wind turbines. IEEE Power Electronic Magazine, 2(3), 16-30. https:// doi.org/10.1109/MPEL.2015.2447631

Moir, I., \& Seabridge, A. (2008). Aircraft systems ( $3^{\text {rd }}$ ed.). New York: John Wiley \& Sons.

Moir, I., \& Seabridge, A. (2013). Design and development of aircraft systems $\left(2^{\text {nd }}\right.$ ed.). New York: John Wiley \& Sons.

Moir, I., Seabridge, A., \& Jukes, M. (2013). Civil avionics systems $\left(2^{\text {nd }}\right.$ ed.). New York: John Wiley \& Sons.

Mohan, N. (2012). Power electronics: A first course. New York: John Wiley \& Sons.

Mohan, N., Undeland, T. M., \& Robbins, W. P. (2003). Power electronics: Converters, applications and design (3rd ed.). New York: John Wiley \& Sons.

Nahvi, M. \& Edminister, J. (2003). Electric circuits (4 ${ }^{\text {th }}$ ed.). New York: McGraw-Hill.

Netushil, A. (Ed.). 1978). Theory of automatic control. Moscow, Russia: MIR Publishers.

Nise, N. S. (2011). Control systems engineering ( $6^{\text {th }}$ ed.). New York: John Wiley \& Sons.

Nya, B. H., Brombach, J., \& Schulz, D. (2012). Benefits of higher voltage levels in aircraft electrical systems. In IEEE electrical systems for aircraft, railway and ship propulsion (ESARS), October 16-18, 2012, Bologna, Italy. https://doi.org/10.1109/ESARS.2012.6387381

Ogata, K. (2004). System dynamics (4 ${ }^{\text {th }}$ ed.). Upper Saddle River, NJ: Pearson Prentice Hall.

Phillips, C. L., \& Parr, J. M. (1999). Signals, systems, and transforms ( $2^{\text {nd }}$ ed.). Upper Saddle River, NJ: Prentice-Hall.

Rahal, A. (1991). Design of static frequency converter suitable for aircraft power systems (Master's thesis, Dublin City University). Dublin, Ireland: Author.
Shiao, Y. S., \& Lin, C. E. (1995). A prototype induction generator VSCF system for aircraft. International IEEE/IAS Conference on Industrial Automation and Control: Emerging Technologies, 148-155, 22-27 May, 1995. Taipei. https://doi.org/10.1109/IACET.1995.527554

Sun, J. (2012). Pulse-width modulation. In F. Vasca \&L. Iannelli (Eds), Dynamics and control of switched electronic systems (Chapter 2). London: Springer-Verlag.

Tewari, A. (2005). Modern control design with MATLAB and SIMULINK. Chichester, England: John Wiley \& Sons.

Tolstov, G. P. (1976). Fourier series (translated from Russian). New York: Dover.

Trentin, A., Zanchetta, P., Wheeler, P., \& Clare, J. (2014). Power conversion for a novel AC/DC aircraft electrical distribution system. IET Electrical Systems in Transportation, 4(2), 29-37. https://doi.org/ 10.1049/iet-est.2013.0005

US Department of Defense. (2008). Aircraft electric power characteristics (MIL-STD-704F). Lakehurst, NJ: Author.

US Department of Transportation, Federal Aviation Administration. (2014). Part 25, Airworthiness standards: Transport category airplanes. Washington, DC: Author.

Vadher, V. V., Smith, L. R., \& Williams, S. (1986). Mathematical modelling of a VSCF aircraft generating system. IEEE Transactions on Aerospace and Electronics (IEEE AES), 22(5), 573-582. https://doi. org/10.1109/taes.1986.310724

Wild, T. W. (2008). Transport category aircraft systems (3 ${ }^{\text {rd }}$ ed.). Englewood, CO: Jeppesen.

\section{Appendix A}

\section{Modeling of Synchronous Generator}

We are using synchronous generator (SG) equivalent circuit model in a rotating $d q 0$ frame-of-reference (Bose, 2002; Eid et al., 2010a; Fitzgerald et al., 2003; Jadric, 1998; Khaburi \& Nazempour, 2012). Transformation from the stationary 3- $\phi$ stator quantities into direct $(d)$ and perpendicular quadrature $(q)$ axis is performed in which the $d$-axis is aligned with the field-winding axis and is rotating. Direct and inverse transformation (often referred to as Blondel or Park's) between stator's and rotating $d q 0$ quantities (flux, current, voltage) is symbolically written as (Fitzgerald et al., 2003):

$$
\left[\begin{array}{c}
S_{d} \\
S_{q} \\
S_{0}
\end{array}\right]=\mathbf{T}\left[\begin{array}{c}
S_{a} \\
S_{b} \\
S_{c}
\end{array}\right] \quad\left[\begin{array}{c}
S_{a} \\
S_{b} \\
S_{c}
\end{array}\right]=\mathbf{T}^{-1}\left[\begin{array}{c}
S_{d} \\
S_{q} \\
S_{0}
\end{array}\right]
$$

The transformation matrix (and its inverse) depends on the electrical angle $\theta_{e}$ between the rotor direct or $d$-axis and the stator's stationary a-phase axis. The zero-sequence component $O$ in $d q 0$ method is required to yield unique transformation of the 3- $\phi$ stator quantities as it corresponds to components of armature current which produce no net flux linking the rotor circuits. Under balanced 3- $\phi$ conditions there are no zero-sequence components (Fitzgerald et al., 2003). Only instantaneous and not RMS quantities are considered in $d q 0$ transformation (Fitzgerald et al., 2003). The damper windings, if present, are short circuited 
(Jadric, 1998). The SG model as used in this study can be now described with a system of nonlinear ordinary differential equations (ODE):

1. Torque balance for rotor:

$$
J \frac{d \omega_{m}}{d t}=\tau_{m}-\tau_{e}-B \cdot \omega_{m}
$$

where,

$\frac{d \theta_{m}}{d t}=\omega_{m} \quad \omega_{m}=\frac{2}{p} \omega_{e} \quad \tau_{e}=\frac{3}{2}\left(\frac{p}{2}\right) \cdot\left(\lambda_{d} i_{q}-\lambda_{q} i_{d}\right)$

2. Stator equations:

$$
\begin{aligned}
& v_{d}=-R_{s} i_{d}-\omega_{e} \lambda_{q}+\frac{d \lambda_{d}}{d t} \\
& v_{q}=-R_{s} i_{q}+\omega_{e} \lambda_{d}+\frac{d \lambda_{q}}{d t}
\end{aligned}
$$

where,

$$
\begin{aligned}
& \lambda_{d}=-\left(L_{l s}+L_{m d}\right) \cdot i_{d}+L_{m d}\left(i_{f d}+i_{k d}\right) \\
& \lambda_{q}=-\left(L_{l s}+L_{m q}\right) \cdot i_{q}+L_{m q} i_{k q}
\end{aligned}
$$

3. Field winding equation:

$v_{f d}=R_{f d} i_{f d}-L_{m d} \frac{d i_{d}}{d t}+\left(L_{l f d}+L_{m d}\right) \frac{d i_{f d}}{d t}+L_{m d} \frac{d i_{k d}}{d t}$

4. Damper winding equations:

$$
\begin{aligned}
& 0=R_{k d} i_{k d}-L_{m d} \frac{d i_{d}}{d t}+L_{m d} \frac{d i_{f d}}{d t}+\left(L_{l k d}+L_{m d}\right) \frac{d i_{k d}}{d t} \\
& 0=R_{k q} i_{k q}-L_{m q} \frac{d i_{q}}{d t}+\left(L_{l k q}+L_{m q}\right) \frac{d i_{k q}}{d t}
\end{aligned}
$$

Variables and parameters used in $d q 0$ model are (Bose, 2002; Eid et al., 2010a; Fitzgerald et al, 2003; Jadric, 1998):

- $\omega_{m}:$ rotor speed (mechanical, $\mathrm{rad} / \mathrm{s}$ ),

- $\omega_{e}$ : rotor speed (electrical, $\mathrm{rad} / \mathrm{s}$ ),

- $\theta_{m}$ : rotor angle (mechanical, rad),

- $\tau_{e}$ : electromagnetic torque $(\mathrm{Nm})$,

- $\tau_{m}$ : mechanical torque supplied to generator by prime mover $(\mathrm{Nm})$,

- $p$ : number of poles,

- $B$ : coefficient of rotational friction (mechanical loss),

- $J$ : rotor's moment of inertia $\left(\mathrm{kg} \mathrm{m}^{2}\right)$,

- $v_{d}$ : armature $d$ axis terminal voltage,

- $v_{q}$ : armature $q$ axis terminal voltage,

- $i_{d}$ : armature $d$ axis terminal current,

- $i_{q}$ : armature $q$ axis terminal current,
- $v_{f d}$ : field winding terminal voltage (reflected to the stator),

- $i_{f d}$ : field winding terminal current (reflected to the stator),

- $i_{k d}: d$ axis damper winding current (reflected to the stator),

- $i_{k q}: q$ axis damper winding current (reflected to the stator),

- $\lambda_{d}$ : total armature flux in $d$ axis,

- $\lambda_{q}$ : total armature flux in $q$ axis,

- $R_{S}$ : armature phase resistance,

- $R_{f d}$ : field winding resistance (reflected to the stator),

- $L_{l s}$ : armature phase leakage inductance,

- $L_{l f d}$ : field winding leakage inductance (reflected to the stator),

- $L_{m d}: d$ axis coupling inductance,

- $R_{k d}: d$ axis damper winding resistance (reflected to the stator),

- $L_{l k d}: d$ axis damper winding leakage inductance (reflected to the stator),

- $L_{m q}: q$ axis coupling inductance,

- $R_{k q}: q$ axis damper winding resistance (reflected to the stator),

- $L_{l k q}: q$ axis damper winding leakage inductance (reflected to the stator).

\section{Appendix B}

\section{Power Quality and Computation Essentials}

Periodic currents with a period $T$ can be presented most generally in terms of the Fourier series (Hart, 2011; Nahvi \& Edminister, 2003, Mohan et al., 2003, Phillips \& Parr, 1999):

$$
\begin{array}{r}
v(t)=V_{0}+\sum_{n=1}^{\infty} V_{n} \sin \left(n \omega t+\theta_{n}\right) \\
i(t)=I_{0}+\sum_{m=1}^{\infty} I_{m} \sin \left(m \omega t+\psi_{m}\right)
\end{array}
$$

The effective or root-mean-square (RMS) values of voltage and current in a single-harmonic sinusoidal signal are defined as:

$$
\begin{gathered}
V_{\text {eff }}=V_{R M S}=\sqrt{\frac{1}{T} \int_{0}^{T} v^{2}(t) d t}=\frac{V_{\max }}{\sqrt{2}} \\
I_{\text {eff }}=I_{R M S}=\sqrt{\frac{1}{T} \int_{0}^{T} i^{2}(t) d t}=\frac{I_{\max }}{\sqrt{2}} \approx 0.707 \cdot I_{\max }
\end{gathered}
$$


More generally, for multi-harmonic periodic orthogonal currents:

$$
V_{R M S}=\sqrt{\sum_{n=1}^{N} V_{n, R M S}^{2}} \quad I_{R M S}=\sqrt{\sum_{n=1}^{N} I_{n, R M S}^{2}}
$$

Using Equation (A1), the average or real power is defined as:

$$
\begin{aligned}
P_{\text {avg }}=\frac{1}{T} \int_{0}^{T} v(t) \cdot i(t) d t=\frac{1}{T} \int_{0}^{T}\left[V_{0}+\sum_{n=1}^{\infty} V_{n} \sin \left(n \omega t+\theta_{n}\right)\right] . \\
{\left[I_{0}+\sum_{m=1}^{\infty} I_{m} \sin \left(m \omega t+\psi_{m}\right)\right] d t }
\end{aligned}
$$

Using the property of orthogonal basis functions (all $n \neq m$ components vanishing) and the phase, $\phi_{n}=\theta_{n}-\psi_{n}$ (Nahvi \& Edminister, 2003; Phillips \& Parr, 1999):

$$
\begin{gathered}
P_{\text {avg }}=<p(t)>=\frac{1}{T} \int_{0}^{T} v(t) \cdot i(t) d t=V_{0} I_{0}+ \\
\sum_{n=1}^{\infty} V_{n, R M S} I_{n, R M S} \cos \phi_{n}=P_{0}+\sum_{n=1}^{\infty} P_{n}
\end{gathered}
$$

The relationship between the amplitudes (maximum values) and the RMS values is given by Equation (B2). In DC systems only $V_{0}, I_{0} \neq 0, V_{n}, I_{n}=0, P_{0}=V_{0} I_{0} \neq 0$. In a single-harmonic sinusoidal AC source $\left(V_{1} \neq 0, V_{n}=0\right)$ and DC components zero $\left(V_{0}=0\right)$, applied to nonlinear load with complex current waveform, the real power is expressed as $\left(\phi_{1}=\theta_{1}-\psi_{1}\right)$ :

$$
\begin{gathered}
P=\frac{1}{T} \int_{0}^{T} V_{1} \sin \left(n \omega t+\theta_{n}\right) \cdot\left[I_{0}+\sum_{n=1}^{\infty} I_{n} \sin \left(n \omega t+\psi_{n}\right)\right] d t= \\
V_{1, R M S} I_{1, R M S} \cos \phi_{1}
\end{gathered}
$$

In electrical network with many elements of resistance $(\mathrm{R})$, capacitance $(\mathrm{C})$, and inductance $(\mathrm{L})$, the impedance and the phase shift with inductive $\left(\mathrm{X}_{\mathrm{L}}\right)$ and capacitive $\left(\mathrm{X}_{\mathrm{C}}\right)$ reactances are:

$$
\begin{gathered}
\mathbf{Z}=R+j\left(X_{L}-X_{C}\right)=|\mathbf{Z}| \cdot e^{j \phi}=|\mathbf{Z}| \angle \phi \\
Z=|\mathbf{Z}|=\sqrt{\mathbf{Z} \cdot \mathbf{Z}^{*}}=\sqrt{R^{2}+\left(X_{L}-X_{C}\right)^{2}} \\
\phi=\tan ^{-1}\left[\frac{\operatorname{Re}(\mathbf{Z})}{\operatorname{Im}(\mathbf{Z})}\right]=\tan ^{-1}\left[\frac{\left(X_{L}-X_{C}\right)}{R}\right]
\end{gathered}
$$

If the phase between the current and voltage in sinusoidal signals is $\phi$, the power factor $(\mathrm{PF})$ is defined as $\cos \phi=P F$. Few definitions of power that are of importance and were used here (Hart, 2011; Mohan et al., 2003; Nahvi \& Edminister, 2003):

1. Complex power: $\mathbf{S}=P+j Q=\mathbf{V}_{R M S} \mathbf{I}_{R M S}^{*}=I_{R M S}^{2} \cdot \mathbf{Z}$.

2. Apparent power: $S=|\mathbf{S}|=\sqrt{\mathbf{S} \cdot \mathbf{S}^{*}}=V_{R M S} I_{R M S}=$ $\sqrt{P^{2}+Q^{2}}=|\mathbf{Z}| \cdot I_{R M S}^{2}=P / P F$, and is measured in Volt-Ampere [VA].

3. Reactive power: $Q=\operatorname{Im}[\mathbf{S}]=V_{R M S} I_{R M S} \sin \phi=$ $V_{R M S} I_{R M S} \sqrt{1-P F^{2}}=X \cdot I_{R M S}^{2}$, and is measured in Volt-Ampere-Reactive [VAR].

4. Real (average) power: $P=\operatorname{Re}[\mathbf{S}]=V_{R M S} \cdot I_{R M S} \cdot \cos$ $\phi=V_{R M S} \cdot I_{R M S} \cdot P F=R \cdot I_{R M S}^{2}$, and is measured in Watts [W].

Asterisk in superscript denotes complex-conjugate values (e.g., $\mathbf{I}_{R M S}^{*}$ ), boldfaced letters are vectors (e.g., $\mathbf{Z}$ ), and the imaginary unit is: $j=\sqrt{-1}$. The Total Harmonic Distortion (THD) of a scaled Fourier waveform electrical voltage/current signal using the fundamental harmonics, can be now defined for voltages and currents (Hart, 2011; Mohan et al., 2003):

$$
\begin{gathered}
T H D_{i}=\frac{\sqrt{\sum_{n=2}^{\infty} I_{n, R M S}^{2}}}{I_{1, R M S}}=\sqrt{\frac{I_{R M S}^{2}-I_{1, R M S}^{2}}{I_{1, R M S}^{2}}} \\
T H D_{v}=\frac{\sqrt{\sum_{n=2}^{\infty} V_{n, R M S}^{2}}}{V_{1, R M S}}
\end{gathered}
$$

The ratio of the fundamental frequency RMS signal to the total RMS value is defined as the Distortion Factor (DF):

$$
D F=\frac{I_{1, R M S}}{I_{R M S}}=\sqrt{\frac{1}{1+\left(T H D_{i}\right)^{2}}}
$$

In non-sinusoidal signals, the Displacement Power Factor (DFP) is equal to $\cos \phi$. The overall PF is thus additionally reduced due to non-sinusoidal currents and harmonic distortion:

$$
P F=D F \cdot \cos \phi_{1}=D F \cdot D P F=\frac{D P F}{\sqrt{1+\left(T H D_{i}\right)^{2}}}
$$

\section{Appendix C}

\section{Tuning of PI and PID Controllers}

Proportional-Integral (PI) controllers are very common in automatic control of many industrial processes, systems, and devices (Kilian, 2006; Nise, 2011; Ogata 2004). PI controllers are the most common in applications and are a 
subset of more complex PID controller. Derivative action is often not necessary. The controller acts on the negativefeedback "error" signal, by first producing the correction proportional to the error. Although, not always acting optimally (Kirk, 2004), PID controllers are very common and have proven reliability record in many industries and systems. PID controller can be seen as a special case of lead-lag compensators (Ogata, 2004). Many PID controllers have auto-tuning capability, i.e., they are adaptive (Aström \& Wittenmark, 2008; Ogata, 2004). Proportional or P-control alone cannot remove stead-steady error (friction effects) and thus I-controller is used to accumulate (integrate) the error-time signal and remove steady-state error. However, the I-controller reduces the stability of the entire system (Kilian, 2004; Netushill, 1978). Often leaky (memory-loss) I-controllers are used to prevent overshoot (and instability) in response. Another problem is with the integrator is windup and signal saturation (Kilian, 2006). An output of a general PID controller is:

$$
\begin{aligned}
& P I D=K_{P} \cdot\left[e(t)+\frac{1}{T_{I}} \int e(t) d t+T_{D} \frac{d e(t)}{d t}\right]= \\
& K_{P} e(t)+K_{P} K_{I} \int e(t) d t+K_{P} K_{D} \frac{d e(t)}{d t}
\end{aligned}
$$

When the transfer functions of the process/servomechanism are known the gains can be directly calculated. However, in more complicated processes and where the dynamics and transfer functions are not available or are too complex, a classical Ziegler-Nichols continuous-cycle method can be used to tune proportional, integral, and derivative gains (Kilian, 2006; Ogata, 2004). First all gains are set to zero. In our Simulink ${ }^{\circledR}$ simulation program when setting PID gains, we increase the proportional gain until harmonic oscillations in the output occur at $K_{P, C R}$. The period of the sustained harmonic (undamped) oscillations $T_{C R}$ is noted and the final P-gain is set as: $K_{P}=0.6 K_{P, C R}$, the integral gain becomes $K_{I}=2 / T_{C R}$, and the derivative gain $K_{D}=T_{C R} / 8$. For PI tuning we used the same procedure, but now $K_{P}=0.45 K_{P, C R}$ and $K_{I}=1.2 / T_{C R}$ (Kilian, 2006; Ogata, 2004). Fine tuning is possible as the Zeigler-Nichols method is not optimal (Kirk, 2004) and cannot guarantee best performance for a variety of process dynamics situations. It can be said that a PI controller acts as a lag-compensator in low-frequency region improving low-frequency gain and steady-state accuracy, while a PD controller acts as lead-compensator improving system stability and increasing system bandwidth in high-frequency region. Thus PID is a kind of a lead-lag compensator improving transient response and steady-state accuracy (Ogata, 2004). Unlike lead-lag compensators, PID controllers can be set experimentally in industrial control systems.

\section{Appendix D}

\section{Pulse Width Modulations}

Pulse Width Modulation (PWM) forms the basis of control in power electronics (Sun, 2012). PWM provides a method to decrease THD of load current, while controling frequency and voltage of the output (Hart, 2011). That also results in reduced filter requirements. A disadvantage is a requirement for more complex control circuits. In our 3- $\phi$ inverter design, we are implementing bipolar double-edge (triangular) modulation with the sinusoidal modulation signal with no DC-component. The triangular carrier signal controls the IGBT's switching dynamics (switching control circuit) which is assumed ideal, i.e., the switch dynamics is assumed instantaneous without losses. The modulation or reference signal is sinusoidal low-power voltage created internally by a signal generator at the required fundamental frequency of $400 \mathrm{~Hz}$, and is maintained constant under variable input and load conditions. To best describe the PWM method mathematically, we need double Fourier series representation of independent carrier and modulation signals (Sun, 2012; Tolstov, 1976). The binary PWM output depends on the instantaneous comparison between the carrier and reference signal and can be mathematically represent with (Sun, 2012):

$$
b_{P W M}(t)=\operatorname{sgn}[r(t)-c(t)]
$$

Triangular or double-edge modulation is implemented in our inverter designs. The switching frequency of IGBT's can go up to 50 and even $100 \mathrm{kHz}$ reaching practical maximum of even the most advanced IGBTs, while transmitting and converting about $100 \mathrm{kVA}$ of electrical power. Here, implemented bipolar modulation, the carrier and the reference signals are symmetric about zero (zero DC offset), resulting in vanishing duty ratio. The peakto-peak amplitude of carrier wave is $C_{m}$, and the PWM switches from $-1 / 2$ to $+1 / 2$. The amplitude modulation index is defined here as (Hart, 2011; Mohan et al., 2003; Sun, 2012):

$$
m_{a}=\frac{V_{\text {reference }}}{V_{\text {carrier }}}=\frac{2 V_{1}}{C_{m}} \leq 1
$$

$r(t)=V_{1} \cos \left(2 \pi f_{1} t+\theta_{1}\right) \quad 2 \pi f_{1}=\omega_{1}$

The frequency modulation index/ratio is (Hart, 2011; Mohan et al., 2003):

$$
m_{f}=\frac{f_{\text {carrier }}}{f_{\text {reference }}}=\frac{f_{\text {carrier }}}{f_{1}}
$$


We used $m_{f} \geq 51$ with $f_{1}=400 \mathrm{~Hz}$. Double-edge bipolar modulation function is (Sun, 2012):

$$
\begin{gathered}
b_{P W M}(t)=\frac{m_{a}}{2} \cos \left(\omega_{1} t+\theta_{1}\right)+\sum_{k=1}^{\infty} \frac{2}{k \pi} J_{0}\left(\frac{k \pi m_{a}}{2}\right) . \\
\sin \left(\frac{k \pi}{2}\right) \cdot \cos \left[k\left(\omega_{c} t+\theta_{c}\right)\right]+\sum_{k=1}^{\infty} \sum_{n= \pm 1}^{ \pm \infty} \frac{2}{k \pi} J_{n}\left(\frac{k \pi m_{a}}{2}\right) . \\
\sin \left[\frac{(k+n) \pi}{2}\right] \cdot \cos \left[k\left(\omega_{c} t+\theta_{c}\right)+n\left(\omega_{1} t+\theta_{1}\right)\right]
\end{gathered}
$$

The initial phases of the carrier and reference signals are $\theta_{c}$ and $\theta_{1}$ respectively and $2 \pi f_{c}=\omega_{c}$. Bessel functions of the first kind in complex variable $z$ and positive integer and zero order $n$ are defined as (Abramowitz \& Stegun, 1984; Sun, 2012):

$$
J_{n}(z)=\frac{j^{-n}}{\pi} \int_{0}^{2 \pi} \exp (j z \cos \theta) \cdot \exp (j n \theta) d \theta
$$

The bipolar switching in full-bridge inverter causes the signal to be $+V_{D C}$ or $-V_{D C}$ using comparator. The control signal modulates the duty ratio of a switch. Blanking time is added in real electronic switches (or IGBTs here) to prevent shorts. Every switch will have its control circuit that governs open-close dynamics and coordinates it with other switches in an inverter. In the case when $V_{\text {reference }}>V_{\text {carrier }}$, the output voltage is commanded at $+V_{D C}$. In the case when $V_{\text {reference }}<V_{\text {carrier }}$, the output voltage is $-V_{D C}$. More details on switching logic by comparing carrier (triangular) and reference (control, modulating) signals are sufficiently well described in Bose (2002), Hart (2011), Luo and Ye (2010), and Mohan et al. (2003). For 3- $\phi$ PWM, three reference voltage signals $120^{\circ}$ apart are generated. For the linear modulation region where $m_{a} \leq 1$, the inverter's output fundamental harmonic voltage is proportional to the modulation (control, reference) voltage:

$$
V_{a 0}=\frac{m_{a} V_{D C}}{2} \sin \left(\omega_{1} t\right)
$$

The harmonics in the inverter output voltage waveform appear as sidebands centered about the switching frequency and its multiples $\mathrm{km}_{f}$ (Mohan et al., 2003). Frequency modulation ratio $m_{f}$ should be an odd integer (e.g., 21, 23, $\ldots, 51,53, \ldots$ ) so that even harmonics disappear from the output voltage waveform as odd symmetry $f(-t)=-f(t)$ exists (Mohan et al., 2003). Generalized harmonics of fundamental-frequency output voltage as function of amplitude modulation index are given in Mohan and colleagues (2003, p. 207).
A load current in a positive pulsed $\left(+V_{D C}\right)$ series $\mathrm{RL}$ circuits starting from zero at initial time increases asymptotically as:

$$
i(t)=\frac{V_{D C}}{R}[1-\exp (-t / \tau)] \quad \tau=\frac{L}{R}[\mathrm{sec}]
$$

When the voltage pulse goes to zero for, $t \geq T$, the current decreases exponentially from the finite value toward zero as, $i(t \geq T)=I_{0}(t=T) \cdot \exp (-t / \tau)$. By changing the positive or negative pulse width, the load currents can be controlled to assume approximately sinusoidal shape. Passive and/or active filters are used to remove as much ripple currents as required by design.

\section{Appendix E}

\section{Passive Filters Design Essentials}

Analog low-pass (LP) passive filters were used at several locations in the DC-Link VSCF design to remove higher-order harmonics, ripple currents, and improve THD. A first-order passive LP filter is illustrated in Figure E1.

If we first consider simpler RC (first-order Butterworth) LP filter, the voltage ratio across the capacitor and the phase angle are (Nahvi \& Edminister, 2003; Fink \& Christiansen, 1989):

$$
\begin{aligned}
|\mathbf{G}(j \omega)| & =\left|\frac{\mathbf{V}_{\text {out }}}{\mathbf{V}_{\text {in }}}\right|=\frac{X_{C}}{Z}=\frac{X_{C}}{\sqrt{R^{2}+X_{C}^{2}}} \\
\phi & =\tan ^{-1}\left(\frac{X_{C}}{R}\right)
\end{aligned}
$$

The phase shift is $\pi / 2-\phi$. The logarithmic gain in $\mathrm{dB}$ is: $20 \log _{10}\left(V_{\text {out }} / V_{\text {in }}\right) \leq 1$. The capacitive reactance is:

$$
X_{C}=\frac{1}{2 \pi f C}[\Omega]
$$

In a pure $\mathrm{RC}$ filter (inductance is zero) when $R=X_{C}$, the power dissipated is half the apparent power $(-3 \mathrm{~dB})$ and the phase angle becomes $45^{\circ}$ designating the cut-off frequency: $f_{C}=1 /(2 \pi R C)[\mathrm{Hz}], \phi=\tan ^{-1}(1)=\pi / 4[\mathrm{rad}]$.

The bandwidth of an LP filter includes all frequencies from zero to the cut-off frequency $\left(70.7 \% \mathrm{~V}_{\text {out }}\right.$ attenuation). This can be easily visualized in Bode's plots or frequencyresponse curves (for gain and phase shift). After passing the cut-off frequency point, the response of the circuit decreases (roll-off) at a constant slope of -20 dB/Decade (or $-6 \mathrm{~dB} /$ Octave). Thus for high frequencies (or harmonics) the capacitive reactance is low (impedance is mostly Ohmic resistance), the output voltage is attenuated, and the potential across the capacitor lags the current, while the phase shift increases toward $90^{\circ}$. When the voltage frequencies 


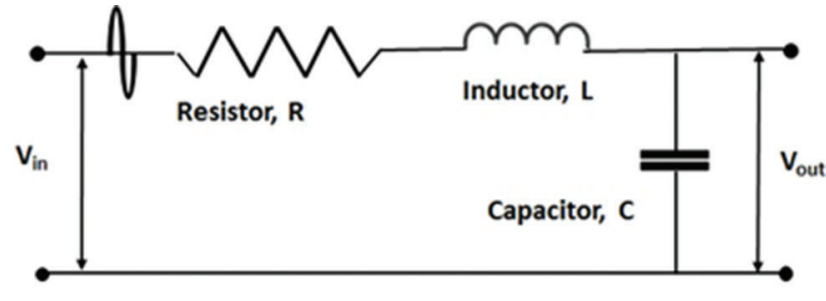

Figure E1. Passive analog RLC second-order LP Butterworth filter.

are low (passband), the capacitive reactance is high compared to Ohmic resistance $R$ and the gain attenuates very little from unity, while the phase shift remains very small. Such first-order (one-pole) passive LP RC filter is simplest way to remove unwanted higher harmonics although the gain attenuation is not very steep. For a single-tuned band-pass (BP) RLC filter (Figure E1), we obtain the resonance frequency and the quality factor Q:

$$
\begin{gathered}
X_{C}=X_{L} \quad \frac{1}{2 \pi f C}=2 \pi f L[\Omega] \quad \Rightarrow \\
f_{r}=\frac{1}{2 \pi \sqrt{L C}}[\mathrm{~Hz}] \quad Q=\frac{1}{R} \sqrt{\frac{L}{C}}
\end{gathered}
$$

Typically the resistor is chosen so as to have $20 \leq Q \leq 100$. Higher Q means less damping (larger amplitudes), but narrower bandwidth. Higher-order passive filters are possible and active filters could be used as well (Eid et al., 2010a, 2010b). An example of a $2^{\text {nd }}$-order highpass (HP) filter would be to use an inductor and resistor in parallel and then in serial connection with a capacitor. Very common in practice are Butterworth (or maximally flat magnitude/gain) filters of $n$th order (first, second, third, fourth, etc.) with the transfer-function magnitude:

$$
|\mathbf{G}(j \omega)|=\frac{G_{0}}{\sqrt{\left(1+\omega^{2 n}\right)}}
$$

Higher-order linear analog Butterworth filters are obtained by cascading lower-order Butterworth filters (Cauer or elliptic topology) consisting of passive lumped shunt capacitors and series inductors. The gain attenuation rate (descent) using Butterworth filters will go as $-20 \times n \mathrm{~dB} /$ decade or $-6 \times n \mathrm{~dB} /$ octave (Fink \& Christiansen, 1989; Phillips \& Parr, 1999). Butterworth filters of very high order complicate design and will have adverse effect on the time-domain response. Chebyshev filters will deliver sharper cutoff and steeper descent through transition region into stopband (SB) at a price of some ripples in the passband (PB). The use of active filters (Grigsby, 2007) complicates the design and requires separate control. We found that simple first-order LP $\mathrm{RC}$ filter sufficed in many instances and satisfied ANSI/IEEE Std. 519 as well as MIL-STD-704F. In a DC circuit the RC layout and the voltage drop across the capacitor will also act as a LP filter and remove higher-order ripple currents after rectification.

\section{Abbreviations}

$$
\text { AC }
$$

A

yㅏㅁ

\section{$\mathrm{CF}$}

CFR

CS

$\mathrm{CSCF}$

CSD

$\mathrm{DC}$

DOD

EASA

EHA

EPS

FAA

FADEC

FAR

FFT

GPU

GTO

HP

HP

HVAC

HVDC

IDG

IEEE

IGBT

LP

LP

MEA

MIL

MOSFET

MTOW

NPT

ODE(s)

PD

PF

PI

PID

PMA

PMG

PT

PWM

RAT

RC

RL

RLC

RMS

RPM

RPS

SCR

SFC

SG

SRM

STD

THD

TOGA

TRU

VA

VAR
Alternating Current

Airplane Operating Manual

Auxiliary Power Unit (aircraft)

Aeronautical Radio, Incorporated

Air Transportation Association of America

Bipolar Junction Transistor (electronics)

Band-Pass (filter - electronics)

Constant Frequency

Code of Federal Regulations (FARs)

Certification Specification (EASA)

Constant Speed Constant Frequency

Constant Speed Drive

Direct Current

Department of Defense (US)

European Aviation Safety Agency

Electro-Hydrostatic Actuators

Electrical Power Systems

Federal Aviation Administration (US)

Full Authority Digital Engine Control

Federal Aviation Regulations (FAA)

Fast Fourier Transform

Ground Power Unit

Gate Turn-Off (thyristor, eletronics)

High-Pass (filter - electronics)

High-Pressure $\left(\mathrm{N}_{2}\right.$ spool - jet engine)

High-Voltage AC

High-Voltage DC

Integrated Drive Generator (CSD + AC generator)

Institute of Electrical and Electronics Engineers

Insulated Gate Bipolar Transistor

Low-Pass (filter - electronics)

Low-Pressure $\left(N_{1}\right.$ spool - jet engine)

More Electric Airplane

Military

Metal-Oxide-Semiconductor Field-Effect Transistor

Maximum TakeOff Weight (aircraft)

Non-Punch Through (IGBT)

Ordinary Differential Equation(s)

Proportional-Derivative (controller, action)

Power Factor

Proportional-Integral (controller, action)

Proportional-Integral-Derivative (controller, action)

Permanent Magnet Alternator

Permanent Magnet Generator

Punch Through (IGBT)

Pulse Width Modulation

Ram Air Turbine

Resistance-Capacitance (circuit, filter)

Resistance-Inductance (circuit, filter)

Resistance-Inductance-Capacitance (circuit, filter)

Root-Mean-Square

Revolutions Per Minute

Revolutions Per Second

Silicon Controlled Rectifier (electronics)

Specific Fuel Consumption (jet engine)

Synchronous Generator (electrical)

Switched Reluctance Machine/Motor (electrical)

Standard

Total Harmonic Distortion (subscript: v - voltage, i - current)

TakeOff Go-Around (thrust).

Transformer Rectifier Unit (electrical)

Volt-Ampere (unit of apparent electric power)

Volt-Ampere-Reactive (unit of reactive electric power) 


$\begin{array}{ll}\text { VAC } & \text { Volts AC } \\ \text { VDC } & \text { Volts DC } \\ \text { VF } & \text { Variable Frequency } \\ \text { VSCF } & \text { Variable Speed Constant Frequency } \\ \text { VSI } & \text { Voltage Source Inverter } \\ \text { W } & \text { Watt (unit of real electric power) } \\ \text { WF } & \text { Wild Frequency }\end{array}$

Eduardo Francis Carvalho Freitas was born in Rio de Janeiro, Brazil. He graduated with a degree in electrical engineering from ETEPFaculdade de Tecnologia de São José dos Campos, Brazil. Currently, he is a graduate student of Mechatronics Engineering at UNITAUUniversidade de Taubate, Brazil. He was formerly a scholarship student sponsored by the CAPES at Minnesota State University, Mankato, as part of a sandwich degree. He spent part of 2014 and the entire year 2015 as an exchange student in electrical engineering at the Minnesota State University in Mankato, MN, while also taking aviation/ aeronautics courses. His research interests include automation, power electronics, aircraft electrical power systems, smart grid, wind power, and renewable energy. Mr. Freitas lives just few miles from the Embraer's main factory in São José dos Campos.

Dr. Nihad E. Daidzic is president of AAR Aerospace Consulting, L.L.C. $\mathrm{He}$ is also a full professor of Aviation, adjunct professor of Mechanical Engineering, and research graduate faculty at Minnesota State University, Mankato. His Ph.D. is in fluid mechanics and Sc.D. in mechanical engineering. He was formerly a staff scientist at the National Center for Microgravity Research and the National Center for Space Exploration and Research at NASA Glenn Research Center in Cleveland, OH. He has also held various faculty appointments at Vanderbilt University, University of Kansas, and Kent State University. His current research interest is in theoretical, experimental, and computational fluid dynamics, micro- and nano-fluidics, aircraft stability, control, and performance, mechanics of flight, aircraft systems, and aerospace propulsion. Dr. Daidzic is ATP and "Gold Seal" CFII/MEI/CFIG with flight experience in airplanes, helicopters, and gliders. 